\title{
Getting in control of persistent, mobile and toxic (PMT) and very persistent and very mobile (vPvM) substances to protect water resources: strategies from diverse perspectives
}

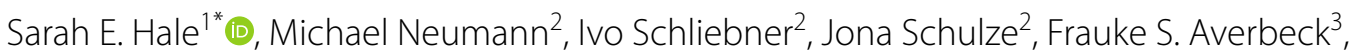
Claudia Castell-Exner ${ }^{4}$, Marie Collard ${ }^{5}$, Dunja Drmač ${ }^{6}$, Julia Hartmann ${ }^{7,8}$, Roberta Hofman-Caris 9 , Juliane Hollender ${ }^{10,11}$, Martin de Jonge ${ }^{12}$, Thomas Kullick ${ }^{13}$, Anna Lennquist ${ }^{14}$, Thomas Letzel ${ }^{15}$, Karsten Nödler ${ }^{16}$, Sascha Pawlowski ${ }^{17}$, Ninja Reineke ${ }^{18}$, Emiel Rorije ${ }^{7}$, Marco Scheurer ${ }^{16}$, Gabriel Sigmund ${ }^{19}$, Harrie Timmer ${ }^{20}$, Xenia Trier ${ }^{21}$, Eric Verbruggen ${ }^{7}$ and Hans Peter H. Arp ${ }^{1,22}$

\begin{abstract}
Background: Safe and clean drinking water is essential for human life. Persistent, mobile and toxic (PMT) substances and/or very persistent and very mobile (VPvM) substances are an important group of substances for which additional measures to protect water resources may be needed to avoid negative environmental and human health effects. PMT/VPVM substances do not sufficiently biodegrade in the environment, they can travel long distances with water and are toxic (those that are PMT substances) to the environment and/or human health. PMT/VPvM substance research and regulation is arguably in its infancy and in order to get in control of these substances the following (non-exhaustive list of) knowledge gaps should to be addressed: environmental occurrence; the suitability of currently available analytical methods; the effectiveness and availability of treatment technologies; the ability of regional governance and industrial stewardship to contribute to safe drinking water while supporting innovation; the ways in which policies and regulations can be used most effectively to govern these substances; and, the identification of safe and sustainable alternatives.
\end{abstract}

Methods: The work is the outcome of the third PMT workshop, held in March 2021, that brought together diverse scientists, regulators, NGOs, and representatives from the water sector and the chemical sector, all concerned with protecting the quality of our water resources. The online workshop was attended by over 700 people. The knowledge gaps above were discussed in the presentations given and the attendees were invited to provide their opinions about knowledge gaps related to PMT/VPVM substance research and regulation.

Results: Strategies to closing the knowledge, technical and practical gaps to get in control of PMT/VPVM substances can be rooted in the Chemicals Strategy for Sustainability Towards a Toxic Free Environment from the European Commission, as well as recent advances in the research and industrial stewardship. Key to closing these gaps are: (i) advancing remediation and removal strategies for PMT/VPVM substances that are already in the environment, however this is not an effective long-term strategy; (ii) clear and harmonized definitions of PMT/vPvM substances across

\footnotetext{
*Correspondence: sarah.hale@ngi.no

${ }^{1}$ Norwegian Geotechnical Institute (NGI), Ullevål Stadion, P.O. Box 3930,

0806 Oslo, Norway

Full list of author information is available at the end of the article
}

\section{Springer Open}

(c) The Author(s) 2022. Open Access This article is licensed under a Creative Commons Attribution 4.0 International License, which permits use, sharing, adaptation, distribution and reproduction in any medium or format, as long as you give appropriate credit to the original author(s) and the source, provide a link to the Creative Commons licence, and indicate if changes were made. The images or other third party material in this article are included in the article's Creative Commons licence, unless indicated otherwise in a credit line to the material. If material is not included in the article's Creative Commons licence and your intended use is not permitted by statutory regulation or exceeds the permitted use, you will need to obtain permission directly from the copyright holder. To view a copy of this licence, visit http://creativecommons.org/licenses/by/4.0/. 
diverse European and international legislations; (iii) ensuring wider availability of analytical methods and reference standards; (iv) addressing data gaps related to persistence, mobility and toxicity of chemical substances, particularly transformation products and those within complex substance mixtures; and (v) advancing monitoring and risk assessment tools for stewardship and regulatory compliance. The two most effective ways to get in control were identified to be source control through risk governance efforts, and enhancing market incentives for alternatives to PMT/VPVM substances by using safe and sustainable by design strategies.

Keywords: Water protection, Regulation, Governance, Stewardship, Prevention, Remediation

\section{Introduction}

PMT/vPvM substances as a threat to water security (H.P.H. Arp, C. Castell-Exner, S.E. Hale and X. Trier)

Safe and clean drinking water is essential for human life. The European Drinking Water Policy began in the 1980s with the aim to ensure that water intended for human consumption is consumed safely on a life-long basis and as such guarantees a high level of health protection. In order to meet the set of legal requirements stipulated by current policies, water suppliers must have access to adequate and reliable drinking water resources that are protected from chemical pollution and other threats. Ideally, these drinking water resources should have a natural status or should only have to be treated using natural or conventional techniques, like sand filtration or aeration, to meet drinking water quality standards. In this way, unnecessary consumer costs are avoided while conserving water's pristine qualities.

It is possible to manage the threat from chemical pollution in such a way that harm to human health and the ecosystem is minimized. This has been demonstrated over recent decades in areas such as the Rhine River Basin [1]. However, as the chemical industry continuously innovates, currently developed tools for environmental risk assessment struggle to keep up with the diversity of chemicals and their uses [2]. Pollution occurs across the whole life cycle of a product from its production until its final disposal, whilst regulation typically only addresses the point at which products are placed on the market, which is only a small part of that lifecycle [3]. The increasing amount and diversity of emerging chemicals on the EU market that can enter water resources, means it is important to consider whether changes to chemical and water resources management need to be made in order to inexpensively safeguard water resources in their natural state.

Persistent, mobile and toxic (PMT) substances and/or very persistent and very mobile (vPvM) substances present an important example where additional measures to protect water resources may be needed to avoid negative environmental and/or human health effects [4]. Owing to their persistent nature, they do not sufficiently biodegrade in the environment and this can result in pervasive contamination if they are emitted in substantial quantities. In the content of this paper, mobility of PMT/vPvM substances refers to the fact that they can travel long distances with water, even in the subsurface and thus are able to spread over large spatial and temporal scales. This means it may be difficult to relate the point of pollution release to the final point of contamination. Concurrently these substances can present a threat to planetary boundaries [5]. If continuously emitted into freshwater systems, and not removed, concentrations of PMT/ vPvM substances will gradually increase and they will be detected in more areas. As many PMT/vPvM substances are extremely difficult to remove from water resources especially when waste water is recycled for drinking water purposes, exposure will also increase with continuing emissions [6-8]

PMT/vPvM substance research and regulation is arguably in its infancy [9-13] and several gaps have already been outlined [14]. In order to forward knowledge related to these substances the following (non-exhaustive list of) gaps should be addressed: environmental occurrence; the suitability of currently available analytical methods; the effectiveness of treatment technologies; the ability of regional governance and industrial stewardship to contribute to safe drinking water and environmental protection while supporting innovation; the ways in which (new) policies and regulations can be used most effectively to govern these substances; and, the identification of safe and sustainable alternatives. Many of these knowledge gaps were discussed at the "Third PMT Workshop: Getting control of PMT and vPvM substances under REACH", which took place on the 25th and 26th of March 2021 (online) which was attended by over 700 people.

\section{Structure of this paper}

This paper presents a summary of the state of play for PMT/vPvM substances from many of the workshop presenters with diverse backgrounds, including chemical and water regulators, analytical and environmental chemists, representatives from environment and health non-government organisations, and industry representatives from the chemical production and water services 
sectors. Each section of the paper is written by a subset of coauthors, as indicated. The perspectives from this author group are bought together to present new ideas of how PMT/vPvM substances can be brought under control in order to protect water resources, particularly for those substances registered under REACH (Regulation 1907/2006 on the registration, evaluation, authorisation and restriction of chemicals). The knowledge gaps and perspectives are presented below by drawing on the toxic free hierarchy presented in the recently published "Chemicals Strategy for Sustainability Towards a Toxic Free Environment" [15]. Figure 1 schematically illustrates the toxic free hierarchy for $\mathrm{PMT} / \mathrm{vPvM}$ substances, where the preferred options in green and at the top of the hierarchy are to prevent use of PMT/vPvM substances, followed by strategies to minimize and control PMT/vPvM substances in orange and in the middle and, finally, the least preferred solution is to remediate PMT/vPvM substances, illustrated in red at the bottom. This article begins by introducing $\mathrm{PMT} / \mathrm{vPvM}$ substances that are currently in the spotlight, then outlines strategies that can be used to get in control of analytical and monitoring methods for PMT/ vPvM substances to set the stage, and this is followed by discussing options upward through the toxic-free hierarchy; remediation, minimisation and control and, finally prevention strategies. To conclude the paper, survey results from the third PMT workshop are used to highlight opinion related to what the largest knowledge gaps are that need to be closed to get in control of PMT/vPvM substances.

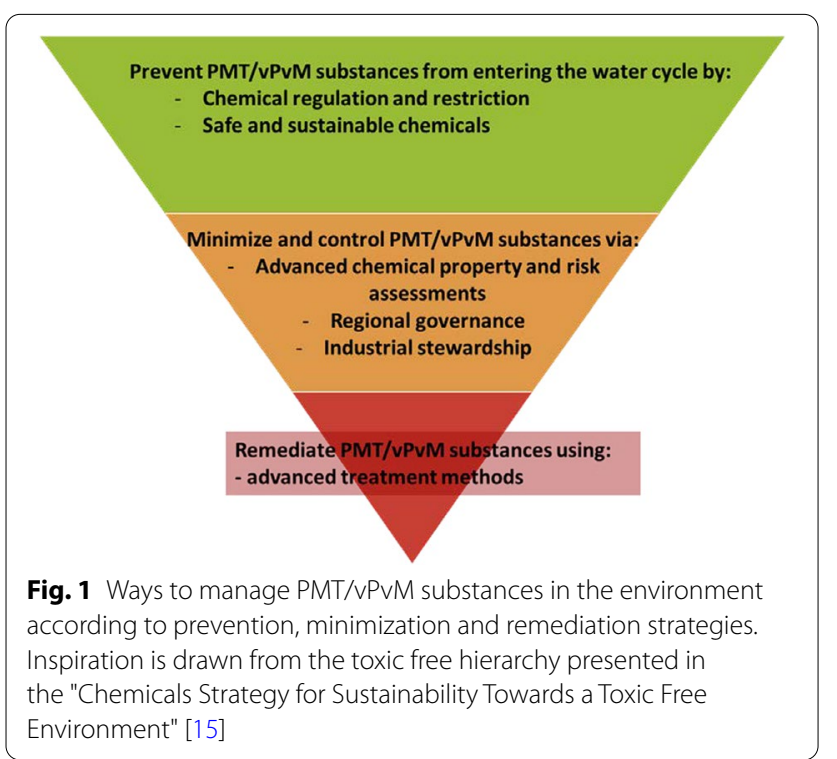

\section{PMT/vPvM substances in the spotlight}

The examples of PMT/vPvM substances below reflect those discussed at the third PMT workshop. These are by no means exhaustive and the reader is referred to additional literature containing extensive lists of substances identified as PMT/vPvM substances. [16].

\section{Trifluoroacetate (TFA) (K. Nödler and M. Scheurer)}

In 2016, elevated concentrations $(10-20 \mu \mathrm{g} / \mathrm{L})$ of the chemical trifluoroacetate (TFA) (or trifluoroacetic acid, TFAA) were detected in tap water samples from a major city in Baden-Württemberg, Germany. Wastewater discharge from an industrial company was later identified as the source of the contamination to bank filtrate which was used to produce tap water. Extended monitoring showed a measurable impact on the drinking water supply along the lower River Rhine [17]. TFA does not have a significant degradation pathway and this results in accumulation in the aquatic environment. This persistence, combined with the mobility of TFA and a lack of suitable water treatment options, presents a highly relevant and complex problem to solve in order to minimize and control exposure [17].

In addition to industrial emissions there are many other primary product and process sources that emit TFA directly, as well as secondary sources which are synthetic substances that form TFA in the environment. For example, the photochemical degradation of certain propellants, refrigerants and blowing agents [18] as well as the (bio)degradation of various compounds from other substance classes (e.g. pesticides and pharmaceuticals), all result in TFA formation [17, 19, 20]. Current monitoring studies show that TFA is a common contaminant in tap water [17], food crops [21] as well as in beer and tea [22] and, consequently, TFA was recently detected in blood samples from the general population (Chinese adult men and women, detection rate $97 \%$, median $8.5 \mu \mathrm{g} / \mathrm{L}$ ) [23]. In addition, recent studies investigating ice cores from the Arctic [24] and precipitation in Germany [25] have confirmed increasing TFA levels in the environment from the 1990s demonstrating the ubiquitous nature of this substance. The toxicity of TFA in animals and aquatic systems is rather low. However, the microalga Raphidocelis subcapitata (formerly known as Selenastrum capricornutum) was identified as the most sensitive species [26] and the NOEC of $0.12 \mathrm{mg} / \mathrm{L}$ was shown to be exceeded in a surface water near a TFA discharging industrial facility [17]. For terrestrial plants NOELs and NOECs $>1 \mathrm{mg} / \mathrm{L}$ 
were reported by several authors. A comprehensive summary of toxicity data regarding TFA can be found in Seiber and Cahill [27].

\section{1,4-Dioxane (Ivo Schliebner)}

1,4-dioxane has been found in groundwater and surface water in Germany [11, 28], Spain [29], Belgium [30], the USA and Japan [31-33], as well as detected in drinking water in these and other regions [31,34-36]. 1,4-Dioxane has a plethora of uses. 1,4-Dioxane is a known byproduct during the synthesis of polyethoxylates and polyesters. The widespread uses of polyethoxylates (and polyesters) containing residual concentrations of 1,4-dioxane can result in emissions to the environment, mainly to waste water. It is also a solvent used as an industrial processing aid, but this use is unlikely to result in substantial emissions.

There are several studies that have pointed to the fact that 1,4-dioxane can be attenuated naturally to varying degrees [35, 37, 38]. However, a recent study reported that 1,4-dioxane was only marginally removed during subsurface passage via river bank filtration and that the removal of 1,4-dioxane using an activated carbon filter does not occur in practice [39]. Based on this evidence of high persistency and mobility in the aquatic environment, together with 1,4-dioxane's classification as Carc. $1 \mathrm{~B}$, it is a priority substance for regulatory assessment. At the time of writing this paper 1,4-dioxane was identified as a substance of very high concern under REACH [40], based on its PMT/vPvM properties being considered an equivalent level of concern to persistent, bioaccumulative and toxic substances (PBT), and very persistent, very bioaccumulative $(\mathrm{vPvB})$ substances [10].

\section{Getting in control of analytical methods and monitoring of PMT/vPvM substances \\ Advances in analytical methods for PMT/vPvM substances (J. Hollender and T. Letzel)}

There are many more persistent and mobile substances than TFA and 1,4-dioxane. The previous studies reporting compilation lists of PMT/vPvM substances [11, 12] are dominated by organic molecules with varying polar, ionizable and ionic functional groups. Taking for instance a list of $260 \mathrm{REACH}$ substances that fulfil the $\mathrm{PMT} / \mathrm{vPvM}$ criteria proposed by the German Environmental Agency in 2019 [4, 41], and further classifying them on the basis of 'polarity' according to their log $D_{\text {ow }}, 74$ of the 260 substances (i.e. $29 \%$ ) have a $\log D_{\text {ow }}$ (pH 7) value between 2 and 4, 72 of the 260 substances (i.e. $28 \%$ ) have a $\log \mathrm{D}_{\text {ow }}(\mathrm{pH} 7)$ value between 0 and 2 , and 62 of the 260 substances (i.e. $24 \%$ ) have a $\log \mathrm{D}_{\text {ow }}$
$(\mathrm{pH}$ 7) value $<0$. The other substances (i.e. 19\%) were mixtures and could not be classified or have $\log \mathrm{D}_{\text {ow }}$ $(\mathrm{pH}$ 7) values above 4 . Of the 74, 72 and 62 substances above, 32, 17 and 4 substances, respectively, contained chlorine or bromine; and 1, 18 and 33 substances, respectively, contained amino/acidic groups.

Analytical techniques capable of simultaneously detecting such diverse substance classes over a broad $\log D_{\text {ow }}$ range are advantageous when screening for such a diversity of PMT/vPvM substances that are suspected to be present. However, these methods may encounter challenges related to separation and detection of such substances [42]. Figure 2 illustrates today's chromatographic techniques and their capabilities. For example, super-critical fluid chromatography (SFC) and reversed-phase liquid chromatography (RPLC) coupled to hydrophilic interaction liquid chromatography (HILIC) allows for the analytical determination of substances with $\log \mathrm{D}_{\text {ow }}$ from -9 to +9 [24-26]. This range is much wider than when using the conventional and common reversed-phase chromatography, which is mostly used in commercial laboratories. Due to increasing needs in PMT/vPvM substance analysis, more commercial laboratories are installing a polarity-extended chromatography. The techniques shown in Fig. 2 can be coupled using electrospray ionization with high-sensitivity, high-accuracy and highresolution tandem mass spectrometry (HRMS/MS). With such HRMS/MS systems non-targeted screening (NTS) analysis of 'unknown' PMT/vPvM molecules can be conducted. There are several openly accessible platforms such as XCMS [43], MZmine [44], FORIDENT [45] and patRoon [46], which cover parts of or the entire NTS data evaluation and prioritization

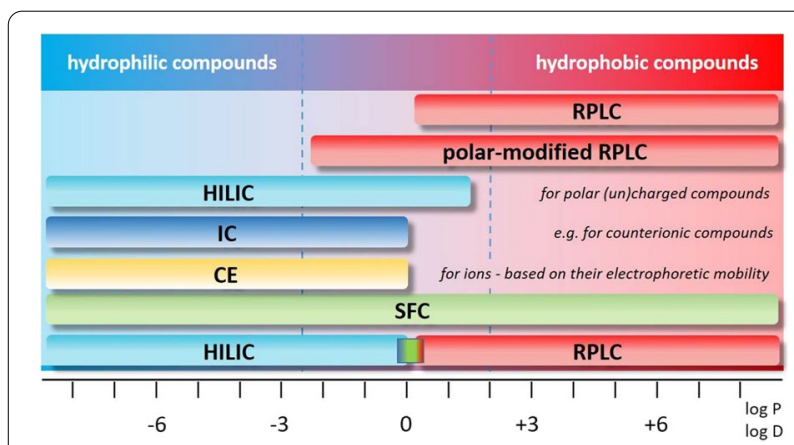

Fig. 2 Polarity scheme for chromatographic (electrophoretic) separation techniques (like reversed-phase liquid chromatography (RPLC), hydrophilic interaction liquid chromatography (HILIC), ion chromatography (IC), capillary electrophoresis (CE) and supercritical fluid chromatography (SFC)) based on log $\mathrm{D}_{\text {ow }}$ values (at several $\mathrm{pH}$ values) of separable molecules and molecule characteristics, [48] adapted with polarity extended chromatography [49] 
process. Using polarity extended chromatography, HRMS, FOR-IDENT and compound databases, several vPvM substances (in the $\log \mathrm{D}_{\mathrm{ow}}$ range from -9 to +9 ) such as $\mathrm{N}, \mathrm{N}^{\prime}$-ethylenedi(diacetamide) [12] or 4-hydroxy-2,2,6,6-tetramethylpiperidine-1-ethanol [47] could be identified in surface waters and other aqueous samples [12, 40, 42-44]. By comparing physicochemical properties of suspect substances with target substances, information can be gained as to whether the suspect substance can be found with a given analytical method. Additional file 1: Fig. S1 shows 1162 PMT/vPvM suspect substances (NORMAN Suspect List S82, https://www.norman-network.com/nds/ $\mathrm{SLE} /$ ) compiled for the Swiss groundwater screening study described below, [50] where approximately $90 \%$ have a predicted $\log \mathrm{D}_{\text {ow }}$ and molecular volume in the same range as almost 500 target compounds that can be detected with polar modified RPLC coupled to electrospray ionization to HRMS.

However, even when polarity-extended chromatographic separations are used, there are still several challenges in the analysis of PMT/vPvM substances. To detect them with sufficient sensitivity in monitoring campaigns, enrichment is often needed; however, very mobile substances are easily lost during conventional enrichment techniques like solid phase extraction (SPE). Vacuum-assisted evaporative enrichment of water samples $[51,52]$, using a combination of several SPE materials including anion and cation exchange materials [53], polarity extended SPE (e.g. [49]) or larger injection volumes (e.g. [54]) are all potential ways to overcome this problem. In addition to the issue with enrichment, identification of unknown substances can be time consuming and reference standards are often needed for the final confirmation of the $\mathrm{PMT} / \mathrm{vPvM}$ substance in question. However, reference standards are often not available, especially for transformation products [55]. It would be very beneficial for the process of detection and confirmation of new contaminants that reference materials or at least substance characteristics such as mass spectra would be provided by industry, such as during the chemical registration process. Finally, prioritization of unknown signals for substance identification is often based on intensity [56] which can be misleading, as the substance in question might not be ionized sufficiently.

In summary, to detect novel PMT/vPvM substances in the environment, suspect screening with appropriate suspect lists and broad-scope analytical methods can be applied successfully, as has been recently demonstrated [42, 50]. In the context of regulatory monitoring it is beneficial to define the targeted $\mathrm{PMT} / \mathrm{vPvM}$ substances as precisely as possible and develop customized methods. A combination of methods might be needed to separate and detect a broad range of PMT substances in a robust way as shown in Schulze et al. [57] and Fig. 2.

\section{Monitoring PMT/VPvM substances in groundwater (H.P.H. Arp, J. Hollender and M. de Jonge)}

Many PMT/vPvM substances have been identified through groundwater monitoring using the analytical techniques described above. In many regions groundwater is the major drinking water resource, providing approximately $50 \%$ of domestic water supply worldwide; in Switzerland this can reach 70 to $80 \%$ [58]. Groundwater is considered better protected from contamination compared to surface water [58], reducing the need for water treatment. Despite this, a broad variety of compounds used in households, industry and agriculture have been reported in groundwater at concentrations in the $\mathrm{ng} / \mathrm{L}$ to $\mu \mathrm{g} / \mathrm{L}$ range [59]. Here two illustrative cases studies are presented, one from Netherlands and one from Switzerland.

The Dutch groundwater survey investigated the presence of 778 organic substances in raw water samples taken from 110 groundwater well fields in 2020 [60]. Most of these well fields are considered vulnerable to pollution in newly formed groundwater, with about $30 \%$ of them being influenced by the infiltration of polluted surface water. Travel times in these groundwater sampling sites range from two years to several hundreds of years. Results from the monitoring showed concentrations of 134 of the 778 monitored organic substances above the analytical detection limit.

The Swiss groundwater study was based on samples from 60 national monitoring sites in Switzerland, and included NTS analysis [50]. The samples were classified as having high or low urban or agricultural influence based on the occurrence of 139 of approximately 500 screened target substances associated with either urban or agricultural sources at the sites. High intensity and frequency of occurrence of unknown peaks associated with potential urban or agricultural sources were investigated further with suspect and non-target screening (for more information see the section "Monitoring data" in the Additional file 1). New substances, not yet reported in groundwater were identified, including the industrial substance 2,5-dichlorobenzenesulfonic acid $\left(\log \mathrm{D}_{\mathrm{ow}, \mathrm{pH}}\right.$ 0.0, 19 detections, up to $100 \mathrm{ng} / \mathrm{L}$ ), phenylphosponic acid $\left(\log \mathrm{D}_{\mathrm{ow}, \mathrm{pH} 7}-2.0,10\right.$ detections, up to $\left.50 \mathrm{ng} / \mathrm{L}\right)$, triisopropanolamine borate $\left(\log \mathrm{D}_{\mathrm{ow}, \mathrm{pH}} 1.5,2\right.$ detections, up to $40 \mathrm{ng} / \mathrm{L}$ ), a transformation product of the blood pressure regulator amlodipine $\left(\log \mathrm{D}_{\mathrm{ow}, \mathrm{pH}}-0.4,17\right.$ detections), and another of the herbicide metolachlor $\left(\log \mathrm{D}_{\text {ow, }}\right.$ 
$\mathrm{pH7}-1.7,33$ detections, estimated concentrations up to $100-500 \mathrm{ng} / \mathrm{L})$.

PMT/vPvM criteria for REACH registered substances have recently been proposed [4] and are currently being discussed for adaptation or modification in a revision to Regulation $1272 / 2008$ on the classification, labelling and packaging of substances and mixtures (CLP), and the REACH regulation (EC No. 1907/2006), [15], as will be discussed more in the "Minimize and Control" section. Of the substances that were detected in either the Dutch or Swiss study, 127 were found to be registered under REACH as of May 2019. It is therefore of interest to see how many of these substances would be considered as PMT/vPvM substances based on the 2019 criteria. By consulting a recently established database of persistency data and experimental $\log \mathrm{K}_{\mathrm{oc}}$ data (similar to Arp and Hale, 2019 [79]), 86 of the 127 substances could be matched with an experimental $\log \mathrm{K}_{\mathrm{oc}}$ within the database. Figure 3 presents a box-plot of these substances, comparing the $\log \mathrm{K}_{\mathrm{oc}}$ with persistency evaluation (raw data can be found in section "Monitoring data used to produce Fig. 3" in the Additional file 1).

As is evident from Fig. 3, most observed substances had a $\log \mathrm{K}_{\mathrm{oc}}<3$ (76 out of 86). In addition, for 57 out of the 86substances, a definitive P conclusion could not be made. For substances monitored in the environment it is common that $\log \mathrm{K}_{\mathrm{oc}}$ data are more commonly available than environmental half-lives [41]. For 8 substances no experimental persistency data, such as readily biodegradable screening tests were available at all; the other 49

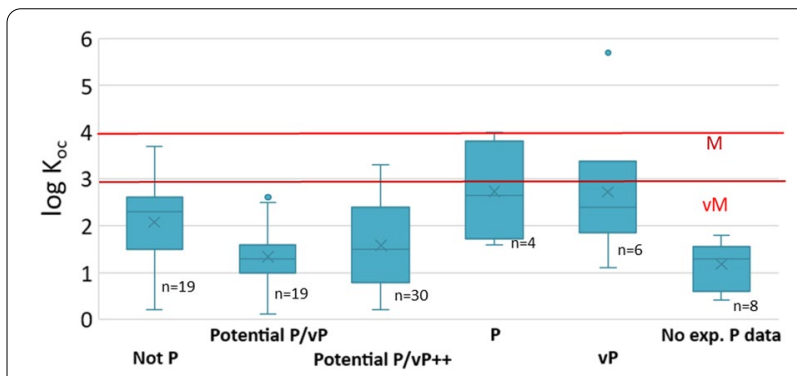

Fig. 3 Box plots of experimental log $\mathrm{K}_{\mathrm{OC}}$ values for REACH registered substances reported in the Swiss or Dutch groundwater survey, grouped according to their persistency classification. See the SI for more information about the monitoring data. Also shown is the PMT/vPVM classification presented in 2019. Briefly, for persistent (P) and very persistent (VP) environmental half-life criteria established in REACH Annex XIII are used [61]; substances that meet the P or VP criterion can be considered "PM" if the minimum experimentally measured $\log \mathrm{K}_{\mathrm{oc}}$ is $<4.0$ (and therefore a PMT substance if additionally found to be toxic), and VP substances can be considered a vPvM substance if there is a minimum experimentally measured $\log \mathrm{K}_{\mathrm{oc}}<3.0$ according to the currently proposed definition of PMT/ VPVM substances [4]. The thresholds of $\log \mathrm{K}_{\mathrm{oc}}<4.0$ (red line) and log $\mathrm{K}_{\mathrm{oc}}<3.0$ (dark red line) are presented of these 57 are considered Potential P/vP (or Potential P/ $\mathrm{vP}++)$ because screening tests indicated they were not readily and/or inherently biodegradable, but they lacked established half-lives to give a definitive P, vP or Not P conclusion. There were 19 detected substances considered "Not P", because they were readily or inherently biodegradable according to screening tests. The presence of "Not P" substances in groundwater could be due to halflives in the environment being much longer than inferred from readily biodegradable screening tests, substantial local emissions, or both. Substantial local emissions are considered an important factor here, as 19 of the detected "not P" compounds were either BTEX components associated with petroleum leakage (5 substances), high production volume phthalates (4 substances), organophosphates (3 substances), or other high-volume commodity substances (p-cymene, bisphenol-a, phenol, aniline, caffeine, tetrahydrofuran and adenosine) that may be emitted from urban areas or landfills [62] (see the Additional file 1: Table S1). In principle, the concentration of these "Not P" substances could be minimized through emission reduction, such as to a point where natural biodegradation would be sufficient for negligible pollution levels (i.e. "natural attenuation").

\section{Remediation and removal \\ Getting in control of treatment technologies for PMT/vPvM substances (G. Sigmund)}

The removal of PMT/vPvM substances from water remains an intense field of research, as no single solution for the removal of all PMT/vPvM substances exists. Their structural and functional diversity, as well as differences in emission sources, calls for a differentiated assessment of treatment technologies.

One of the most widely used advanced water treatment technologies to remove organic contaminants from waters is adsorptive removal via activated carbon. Because of their high porosity, high specific surface area and graphene-like aromatic structures, activated carbons are very good sorbents for aromatic compounds, such as polycyclic aromatic hydrocarbons, polychlorinated biphenyls and other "traditional" persistent organic pollutants (POP) [63], as well as polar and ionizable aromatic compounds which generally sorb efficiently to these graphene-like surfaces [64-66]. Accordingly, activated carbon was recently found suitable for removing 15 pollutants known to be only partly removed in conventional waste water treatment plants, all of which contained aromatic structures [67]. However, many PMT/ $\mathrm{vPvM}$ substances are not aromatic (132 out of the 260 prioritized REACH PMT/vPvM substances are not aromatic [41]), and/or are ionizable or ionic (148 out of 260 prioritized REACH PMT/vPvM substances), which 
complicates their sorption behaviour, as additional electrostatic interactions can occur [66]. For non-aromatic and negatively charged substances, removal rates by activated carbon are often low. A recent study considering PFAS (where some of the individual substances are anionic), revealed generally unsatisfactory removal rates via activated carbon, and anion exchange resins have been suggested as alternative sorbents [68]

For substances where activated carbon or ion exchange resins do not remove them to a sufficient degree, reverse osmosis and nanofiltration can be effective technologies for water purification (Fig. 4). However, these techniques are energy intensive and produce brine (often $25 \%$ of the volume) which has to be disposed or remediated [69]. As an example, TFA, described above, can only be removed by reverse osmosis [17]. Advanced oxidation processes including the use of Fenton's reagent $\left(\mathrm{H}_{2} \mathrm{O}_{2}+\right.$ ferrous ion), photo catalysis $\left(\mathrm{UV}+\mathrm{TiO}_{2}\right)$ or supercritical water oxidation are also proposed for the removal of substances from water [70]. However, oxidation-based processes pose the risk of forming unwanted by-products which may need to be removed by activated carbon as a subsequent step. An overview of these treatment processes, and substances they are most suitable for, is presented in Fig. 4. Each of these treatments have a limited implementation window due to their costs, and none of them are wholly protective. Even these expensive, advanced drinking water treatments in Fig. 4 are not capable of quantitatively removing organic micropollutants such as HFPO-DA, TFA and melamine [71]. The removal of all relevant PMT/vPvM substances needs an ever-increasing combination of technologies. Further, the implementation of many technologies in Fig. 4 undermines the principle of limiting water treatment to natural processes [72]; and are best practiced at the site of initial emissions, before exposure to raw water.

\section{Minimize and control}

Getting in control of substance property assessments to identify PMT/vPvM substances (H.P.H. Arp, J. Hartmann, R.C.H.M. Hofman-Caris, E. Rorije, E. Verbruggen)

Identification of a PMT/vPvM substance well before it is emitted into the environment in large quantities, increases the chances for control. If a high-quality PMT/ vPvM substance assessment could be carried out before a substance is even produced in large volumes, risk management efforts could be put in place to prevent contamination of ground and surface water; or safer alternative chemicals could be used instead. Persistence (P), mobility $(\mathrm{M})$ and toxicity $(\mathrm{T})$ are all intrinsic substance properties related to if the chemical structure is resistant to naturally occurring biodegradation reactions $(\mathrm{P})$, partitions preferably to water from environmental soils and sediments $(\mathrm{M})$, and acts deleteriously with biology at the cellular or ecological level at low levels of chemical activity (T). As P, $\mathrm{M}$ and $\mathrm{T}$ are all dependent on ambient and environmental

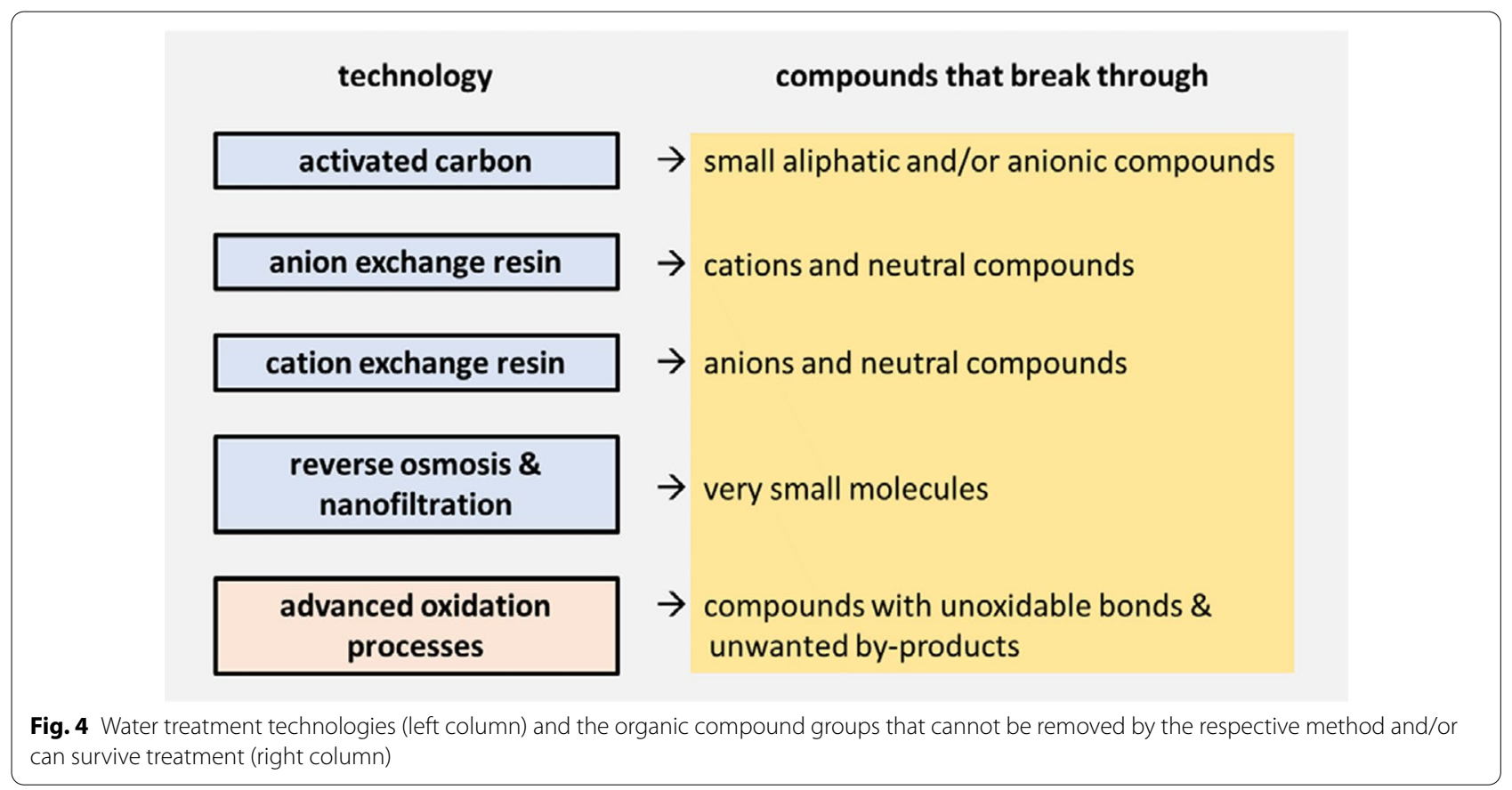


properties (e.g. temperature, nutrient levels, etc.), they are best quantified through standardized tests.

\section{Persistence}

When assessing persistence, Annex XIII of the REACH regulation ((EC) No. 1272/2008) sets half-life thresholds in water, sediment and soil at $12^{\circ} \mathrm{C}$. Substances with halflives exceeding threshold values would meet the classification for $\mathrm{P}$ or vP. For mobile substances, the half-lives in (marine) surface water are particularly relevant, as soil and sediment retain these substances only to a limited extent and surface water is the compartment in which these substances end up. Unfortunately high-quality half-life data are quite rare, even for REACH registered compounds, due to their high cost and difficulty of measurement $[41,73]$. The PBT guideline makes several recommendations to assess persistence, and particularly non-persistence, in the absence of half-lives, such as the use of readily biodegradable or inherently biodegradable screening tests like the OECD Test Guideline 301 and 302 series [61]. Quantitative structure activity relationships (QSARs) can also be used to predict half-lives, but are generally too uncertain for a definitive $\mathrm{P}$ conclusion and are best used for screening [41]. Therefore, simpler approaches are needed to ascertain half-lives of sufficient quality.

In the OECD Guideline 309 "Aerobic Mineralisation in Surface Water-Simulation Biodegradation Test" [74] for assessing biodegradation half-lives, a time course of aerobic primary and ultimate degradation in surface water can be determined using kinetic rate expressions for degradation, mostly performed using ${ }^{14} \mathrm{C}$-labelled compounds. However, it is very difficult to obtain ${ }^{14} \mathrm{C}$ labelled compounds, especially in cases where the compounds are observed for the first time in the aqueous environment. This makes the procedure poorly accessible and very expensive. The OECD 309 test may however, be performed with non-radiolabelled material as well, with a validity criterion for the mass balance of $70-110 \%$. This test with non-radiolabelled materials was recently applied to the following potential PMT/vPvM substances: gabapentin, 1H-benzotriazole, diglyme, DTPA, 1,4-dioxane, melamine and urotropine, identified by Arp and Hale [41] that were at the time not subject to any regulation [75]. For the test, a pure, pristine surface water source from Schalterberg (NL) used for drinking water production was obtained and was tested to confirm the following: i) it did not contain the test substances; ii) it contained very little synthetic chemical contamination, and iii) it contained microbiological activity. The microorganisms in this water had not previously been exposed ("adapted") anthropogenic micropollutants. A spiked stock solution of the PMT/vPvM substances and aniline was then added to this pristine water and stored in the dark at $13{ }^{\circ} \mathrm{C}$. Aniline is used as a benchmarking substance, as its biodegradation behaviour is well-known. At regular time intervals, bottles were removed for chemical analysis to account for changes in concentration of the analytes, alongside adenosine triphosphate (ATP) analysis to account for microbial activity and to account for the possibility of a substance acting as a biocide. Results from the test showed that there was no degradation for gabapentin, $1 \mathrm{H}$-benzotriazole, diglyme, 1,4-dioxane and melamine while for DTPA and urotropine, slow degradation (with half-lives of 68 and over 128 days, respectively) occurred. The degradation half-live of the benchmark substance aniline was 5 days. Based on these results, all tested substances were determined to be very persistent according to REACH Annex XIII, having a half-life in freshwater $>60$ days. As the test was carried out without the need for ${ }^{14} \mathrm{C}$-labelled compounds, the method is more accessible and by far cheaper than the OECD 309 performed with radiolabelled test substances. This example shows that existing guidelines allow for generating high-quality biodegradation data at reduced costs. More details about this test can be found in section "Additional details about the persistency test" Additional file 1.

\section{Mobility}

Mobility assessments are the only truly new part of a PMT/vPvM substance assessment protocol, as the assessments of $\mathrm{P}$ and $\mathrm{T}$ follow the current PBT assessment, with slight modifications. It is emphasized that in the PMT/vPvM criteria under discussion in Europe for inclusion in the CLP and REACH regulations [15], mobility assessments are only required for persistent substances [4]. This is largely based on the rationale presented in the monitoring section that non-persistent substances monitored in groundwater or drinking water, like caffeine (Fig. 3), would disappear more readily from the subsurface if emissions were suddenly reduced or eliminated. Gustafson et al. [76] first suggested the use of the organic-carbon partition coefficient, $\mathrm{K}_{\mathrm{oc}}$, in combination with persistency in terms of soil half-lives, as a way of assessing the potential for subsurface mobility. This combination of $\log \mathrm{K}_{\mathrm{oc}}$ and soil half-lives has been used in the EU biocide regulations [77], and adapted to the discussed PMT/vPvM criteria (with $\log \mathrm{K}_{\mathrm{oc}}<4.0$ and $<3.0$ as the cut-off for $\mathrm{M}$ and $\mathrm{vM}$, respectively, for all $\mathrm{P}$ and $\mathrm{vP}$ substances, not just those persistent in soil). A current proposal from the European Commission for Classification and Labelling (CLP regulation) currently uses log $\mathrm{K}_{\mathrm{oc}}<3.0$ and $<2.0$ as the cut-off for $\mathrm{M}$ and vM [78]. These proposals compared with classifications used in the GUS (Groundwater Ubiquity Score) index as proposed 


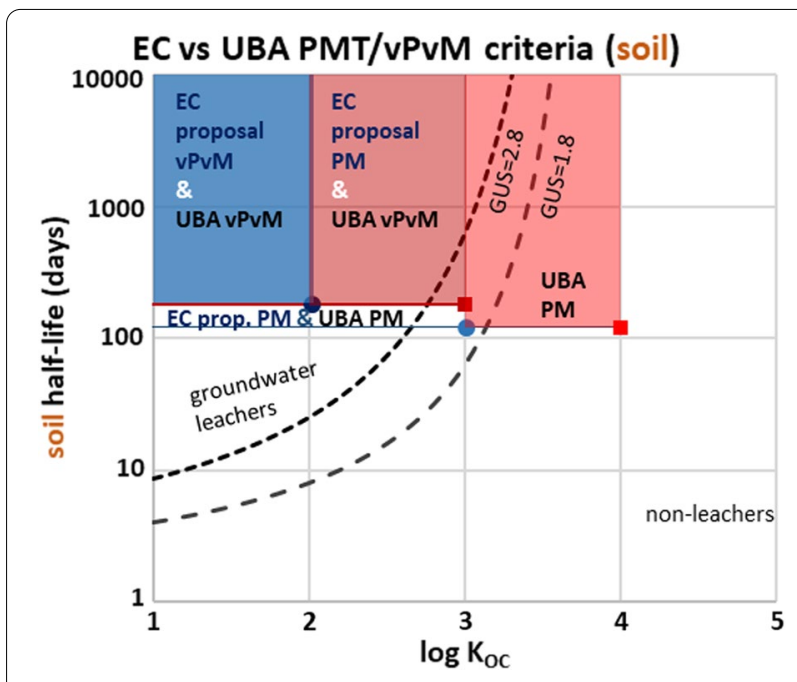

Fig. 5 A groundwater ubiquity score (GUS) showing the thresholds for groundwater leachers (GUS $>2.8$ ), non-leachers (GUS $<1.8$ ), and regions that correspond to the UBA and EC commissions current proposal (Sept 30, 2021) for very persistent, very mobile (vPvM) substances and persistent and mobile substances (PM)

by Gustafson [76] are shown in Fig. 5. The GUS index is based on the equation below:

$$
\text { GUS }=\log \text { DT50 }\left(4-\log \mathrm{K}_{\mathrm{OC}}\right),
$$

Where DT50 is the soil half-life (degradation time$50 \%)$ in days. In this metric, a GUS $>2.8$ is considered a groundwater leacher, a GUS $<1.8$ a non-leacher, and those between 1.8 and 2.8 a transition zone where both are possible. For a half-life of 180 days in soil (the $\mathrm{vP}$ criterion) this would mean a $\log \mathrm{K}_{\mathrm{oc}}$ value of 2.76 as the upper value (rounded to 3 and thus in agreement with the current proposal [4]). With a soil half-life of 120 days (the $P$ criterion) this would lead to a $K_{\mathrm{oc}}$ value 3.13 to match the boarder between "non-leachers" and the transition zone. However, it was argued based on empirical data of chemicals in drinking water, groundwater and breaking through bank filtrate that the $M$ criteria should be a log $\mathrm{K}_{\mathrm{oc}}$ of 4 to be protective of the majority of detected substances in these media [41]. The European Commission in consultation with the PBT expert group of ECHA has proposed to lower these cutoffs to $\log \mathrm{K}_{\mathrm{oc}}$ of 2 and 3 for vM and M, respectively, because " $a$ comparison of criteria provided in different legislations [and] guidance [...] indicate that $\log K_{o c}$ of 4 would include also substances with great adsorption capacity and not likely to be mobile" [78].

The advantage of using $\mathrm{K}_{\mathrm{oc}}$ is that organic carbon is often a good "proxy phase" for soil and sediment sorption, as it is often dominating sorption phase in soils and sediments for neutral organic compounds [79], and even for many ionic organic compounds, as soil organic carbon has a substantial cationic exchange capacity [80]. The major shortcoming with organic carbon as the proxy phase for mobility is that data and models are lacking for ionic and zwitterionic species [81], partly because these ionic interactions could vary widely across types of organic carbon, as well as counterions in the porewater. This is evidenced empirically as $\mathrm{K}_{\mathrm{oc}}$ measurements for ionic and ionizable substances are often quite variable [82], in part due to ionic interactions with soil minerals that can further reduce mobility [83]. Therefore for mobility assessments of ionic substances, a recommended approach is to use the minimum empirical measured $\log \mathrm{K}_{\mathrm{oc}}$ from batch tests with actual soils (where the $K_{D}$ value is corrected using the soil organic carbon content), sediments or sludges as the basis [41]; however, it should be kept in mind for local risk assessments that additional local factors are also important for subsurface mobility (e.g. flow rates, clay content, etc.) [84].

\section{Toxicity}

Toxicity assessments generally follow those defined in REACH Annex XIII for PBT/vPvB assessments. These include the toxicity categories of carcinogenicity, mutagenicity, reproductive toxicity, specific organ toxicity (repeated exposure), freshwater ecotoxicity and more recently also endocrine disruption [15]. Other categories can also play a role, including terrestrial ecotoxicity [78], skin sensitization, and immunotoxicity. It must be noted that for those endpoints based on effect concentrations in environmental media, the same effect caused within the organism should occur at a lower fugacity than for PBT substances, because of the general lower bioaccumulation from these environmental media for PMT substances. Although large amounts of toxicity data are available [16], it cannot always be assumed that such toxicity data sets are complete or reliable. For certain persistent compounds that are widespread in the environment, long time scales of exposure were needed before the mechanisms of toxicity were elucidated [85]. This is part of the justification for the establishment of the vPvM criteria, which does not consider toxicity [4].

\section{Screening and predictive approaches}

Due to the lack of empirical persistency, mobility and toxicity data, it is currently only possible to conduct a high-quality PMT/vPvM substance assessment for a relatively small number of substances [41]. To address this gap, screening and predictive models can be useful to prioritize where further testing is needed. For persistency, this includes readily biodegradable tests (e.g. OECD301A-F, OECD310). For mobility assessments, octanol-water distribution coefficients $\mathrm{D}_{\text {ow }}$ values, 
have been recommended as a screening parameter in the lack of $\mathrm{K}_{\mathrm{oc}}$ data, though there are concerns that $\mathrm{D}_{\mathrm{ow}}$ does not account for ionic interactions with soil $[4,41]$. For toxicity screening the Cramer Class III method has been recommended [86]. A proposal for a more elaborate screening of potential (human health) toxicity by including alert models for carcinogenicity, mutagenicity, reproductive toxicity (CMR) as well as potential endocrine disruption (ED) is described in the supporting information. A discussion of the performance of various quantitative structure activity relationship (QSAR) for predicting persistence and mobility properties has been described in recent articles and reports [12, 41].

Two QSAR approaches to conduct a complete PMT assessment, requiring only the chemical structure as input, have been proposed. One was developed using a Danish QSAR database and was described by Holmberg et al., [87]. The other one was recently developed by the Dutch National Institute for Public Health and the Environment (RIVM), presented in section "Additional details about the RIVM QSAR" Additional file 1, which scores substances on a scale from 0 to 1 , from low to high PMT substance potential. This screening approach also enables separate evaluation of persistence, mobility and toxicity of a chemical structure making a score for P, M and T, and aggregates them using the following function:

$$
\begin{array}{r}
P M T-\text { score }=P-\text { score }^{0.4} * M-\text { score }^{0.4} * \\
\text { T (humanhealth) }- \text { score }^{0.2} .
\end{array}
$$

The two approaches differ. The approach developed by the Danish team only considers mobility for substances that exceed a persistency threshold, and toxicity only for those substances exceeding a persistency and mobility threshold. The approach developed by RIVM considers persistency, mobility and toxicity simultaneously. The approaches also include different toxicity endpoints, but both include QSARs predicting a substance's carcinogenic, mutagenic, reprotoxic and endocrine disruptive potential. The RIVM approach also incorporates toxicity screening based on Cramer Classes. Both approaches consider some human health-related endpoints, while ecotoxicity based on long-term toxicity to fish, daphnia or algae is considered by the Danish team but not in the RIVM approach.

An inherent feature of all QSARs is that they work best for substances that have similar structures to those in their chemical calibration data set, which tend to be neutral substances [12, 88]. Despite this, if the uncertainty of predictions and application domains are taken into careful consideration, QSAR-based screening approaches are a valuable tool for the initial screening of potential PMT substances [89].

\section{Getting in control of PMT/vPvM substances through various types of chemical risk governance $(H$. Timmer)}

The Dutch and Swiss monitoring studies discussed above highlight that drinking water suppliers are faced with an increasing number of known and unknown PMT/vPvM substances in their water sources. Strategies are therefore needed to avoid detrimental effects of pollutants on the quality of water bodies, aquatic life, natural areas and biodiversity. Stricter drinking water threshold concentrations are becoming more and more common; the revised version of the drinking water directive $(98 / 83 / \mathrm{EC})$ [90] is a prominent example. The revision includes several parameters for PFAS concentrations where threshold values are in the ng/L range. The growing gap between detected concentrations of certain PMT/vPvM substances (in addition to other micropollutants) in drinking water sources exceeding the acceptable concentrations in drinking water results in an increasing requirement for purification treatment levels. This has been highlighted in a recent study [91] where a framework was developed to evaluate the required purification treatment level. This framework was applied to Amsterdam and its surroundings from an intake along the river Rhine, the major Dutch river, at Nieuwegein. The results showed that the treatment effort required to provide safe drinking water actually increased between 2000 and 2018, despite the ambitions of the water framework directive (WFD, 2000/60/EC [72]) to reduce the level of purification treatment required. When PMT/vPvM substances were considered alone, as shown in Fig. 6 for the Nieuwegein river intake, the level of purification treatment was even higher [92]. For this evaluation, water quality data for 1161 substances with $P, M$ and/or $T$ assessments from the Dutch PMT Working Group were used. In total, 626 substances were detected, and 91 substances exceeded the target value in the European River Memorandum of $0.1 \mu \mathrm{g} / \mathrm{l}$ at least once between 2000 and 2019. This pollution affects about 3 million people that depend directly on Rhine water (including lake IJssel) and a similar situation is assumed at the Dutch Meuse water intakes. Both rivers provide about $40 \%$ of Dutch drinking water, in areas where fresh groundwater is scarce. Extensive monitoring along the Rhine at the location Lobith identified that the composition of these PMT/vPvM substances changed over time, indicating that some substances were switched with other substances, due to regulatory or commercial forces (Additional file 1: Fig. S2). For example, efforts to identify and reduce the emissions of diglyme, MTBE/ ETBE and pyrazole were effective, whilst the "hot" PMT/ $\mathrm{vPvM}$ substances such as 1,4-dioxane and TFA can be seen to have been introduced during the study period. 


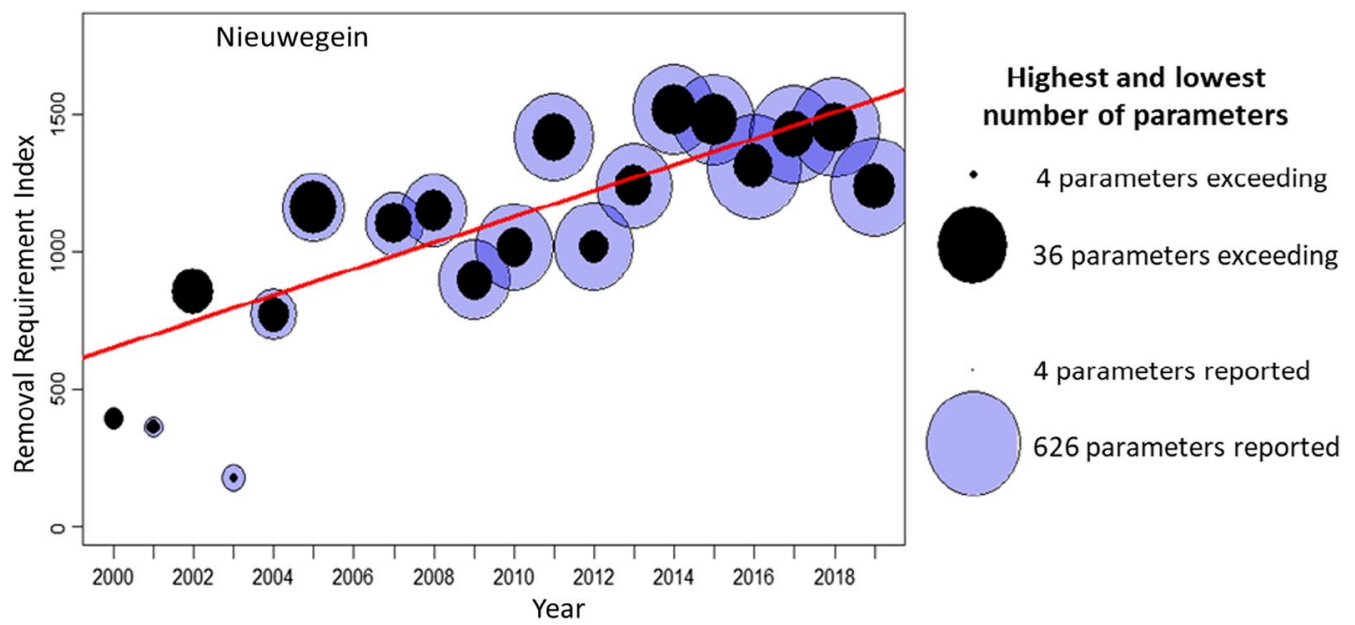

Fig. 6 Removal Requirement Index for PMT substances at the intake of Nieuwegein (River Rhine), based on the methodology of Pronk et al. (2021) as described in https://iwaponline.com/ws/article/21/1/128/77954/A-water-quality-index-for-the-removal-requirement. The Water Quality Removal Requirement Index is an indicator sum parameter that describes the gap between the standards in the Dutch drinking water act, and the quality of the source water. The gap increases when the concentrations of the pollutants increase, or when environmental quality standards are lowered

There are many ambitious goals established via the WFD, the Urban Waste Water Treatment Directive (UWWTD, directive 91/271/EEC) and the Industrial Emissions Directive (IED, directive 2010/75/EU) to protect surface and groundwater from the adverse effects of discharges of urban and industrial waste water. In addition, both the Aarhus convention (1998) and the Kyiv Protocol (2003) provide a transparent ambition for the registration of discharges and emissions. The Aarhus Convention details rights that organisations are entitled to receive environmental information that is held by public authorities. The Kyiv Protocol aims to enhance public access to information on industrial and WWTP emissions through the establishment of coherent, nationwide Pollutant Release and Transfer Registers (PRTRs). The resulting "E-PRTR" is the EU system for collecting and disseminating information about environmental releases and transfers of hazardous substances from industrial and other facilities. Integration and implementation of these regulations could provide a basis for more, and improved, governance of PMT/vPvM substances, as they include risk assessment models and methods that local authorities could put into practice, including a framework for the proper registration of emissions.

Based on the above, it appears that the WFD, the IED, the UWWTD, the Aarhus Convention and the Kyiv Protocol, in combination, provide an adequate framework of relevant environmental legislation and obligation for transparency, at least in theory. However, the results of these frameworks to date have not matched the ambitions set. Reaching good ecological and chemical status for water bodies covered by the WFD by 2027 seems increasingly unlikely [93, 94]. Similarly, results on the transparency of emissions is disappointing as currently available information shows limited quality, completeness, and homogeneity [95]. In contrast to this, steps are being made forward in certain more regional situations. For example, the Dutch system of licensing industrial discharges was revised in 2019 to include a drinking water test as an additional requirement to the existing regulatory WFD ecological and chemical requirements. This ambitious approach is in line with EU regulations and protects drinking water intake and thus human health from PMT/vPvM (and other) substances, by prescribing additional pollution abatement methods. In practice this means that when a discharge of a PMT/vPvM substance is proposed, the effect of this emission for a drinking water company is assessed. If it is found that the discharge could seriously affect the surface water quality, additional purification using the best available technology (BAT) or BAT with additional measures (BAT + ) by the polluter is required, or the license will not be granted.

The current review and revision of the IED and UWWTD provides the opportunity to improve the permitting procedures of $\mathrm{PMT} / \mathrm{vPvM}$ substances and other relevant pollutant emissions in a similar manner. Movement in a common direction could improve internal harmonization between all European regulations. The identification of $\mathrm{PMT} / \mathrm{vPvM}$ substances under REACH as Substance of Very High Concern (SVHC), as proposed by the European Commission in the 
Chemicals Strategy for Sustainability Towards a Toxic Free Environment, could be used by the watershed or river authorities to demand extra purification when these (and other relevant) substances are emitted to the aquatic water environment, and for registration in the in the E-PRTR system. Such an optimized licensing and registration system could lead to improved water quality.

\section{Getting in control of PMT/vPvM substances through chemical industry stewardship (M. Collard, D. Drmač, T. Kullick, S. Pawlowski)}

The chemical industry is constantly improving measures to reduce the release of chemicals into the environment. Successful stewardship measures have been used in the past to reduce major environmental contaminants which led to the increase in both species number and abundance in large urbanised rivers, such as the Rhine [1, 96-98]. Due to improved analytical methods, more substances can be detected at low concentrations including those found in drinking water. In Germany, an initiative launched by the German Federal Environment Ministry (BMU) entitled "Trace substance strategy of the German Environment" is currently underway to tackle this issue. The chemical industry (through the German Chemical Industry-VCI) is strongly contributing to this round table discussion with strategies and options for actions in a multi-stage process.

As part of this work, both chemical properties and use patterns are considered in order to quantify the impact of contaminants found in water on human health and the environment. Whilst persistent and mobile substances may have a higher probability of contaminating groundwater, the amount and use pattern as well as the way it is emitted into the environment are also the major drivers for its detection [84]. This is true of caffeine. Whilst it is not persistent (because it is readily biodegradable) it is a major drinking water contaminant, and was also detected in the Dutch monitoring study mentioned earlier, because it is emitted constantly and daily by millions of people all across Europe [99]. Conversely, a persistent and mobile substance used under strictly controlled conditions with risk management measures in place to avoid release to the environment is unlikely to be a drinking water contaminant. It is apparent, therefore, that to tackle possible contamination of water at concentrations posing a risk to human health and the environment, emission patterns need to be considered in addition to substance properties [55]. A stepwise process: "screenprioritise-assess-control" is useful to minimize environmental and human health risks. This can be assisted by a strong collaboration among local stakeholders, e.g. local industry and drinking water suppliers, especially when considering local pollution caused by an industrial site or an incident. In addition, improvements in risk assessment models such as European union system for the evaluation of substances (EUSES) and SimpleTreat can contribute to providing a more accurate assessment of the current situation. In particular, exposure-based models are well defined for substances entering water via soil leaching. However, another relevant entry pathway is linked to the process of riverbank filtration. Currently, this pathway is not sufficiently covered by existing models and additional research is needed.

It is important that the approach taken to regulate PMT/vPvM substances is harmonized both geographically and across regulations. Within the EU, risk assessment approaches for the protection of drinking water resources (focusing on groundwater) are well established for plant protection products (PPP) and biocidal active products, for deriving Guideline Values for drinking water by the WHO and the Drinking Water Directive, and to some extent under REACH (i.e. man via the environment). The interplay between hazard assessment, risk assessment and risk management in those frameworks is illustrated in Fig. 7.

In the context of establishing a global approach, potential drinking water contaminants can be assessed as the other chemicals under REACH, i.e. a hazard assessment based on the intrinsic properties of the substances with a follow-up risk assessment based on its uses.

\section{Prevention}

\section{Getting in control of PMT/vPvM substances} through regulation (F.S. Averbeck, S.E. Hale, M. Neumann, J. Schulze)

Active steps towards new policies and regulations for PMT/vPvM substances are currently occurring at the highest European level. Upstream preventative approaches are recognised as one of the most effective methods to reduce environmental and human health hazards as well as exposure from harmful substances as part of the Chemicals Strategy for Sustainability Towards a Toxic Free Environment [15]. Key aspects to achieving these goals is the revision of the CLP regulation and the REACH regulation, which are important cornerstones of the EU's regulation of chemicals. Therein, the following action points, related to getting control of PMT/vPvM substances, have been defined:

- create new hazard classes and criteria in the CLP regulation by 2021 ,

- amend Article 57 of REACH to add endocrine disruptors as well as PMT and vPvM substances by 


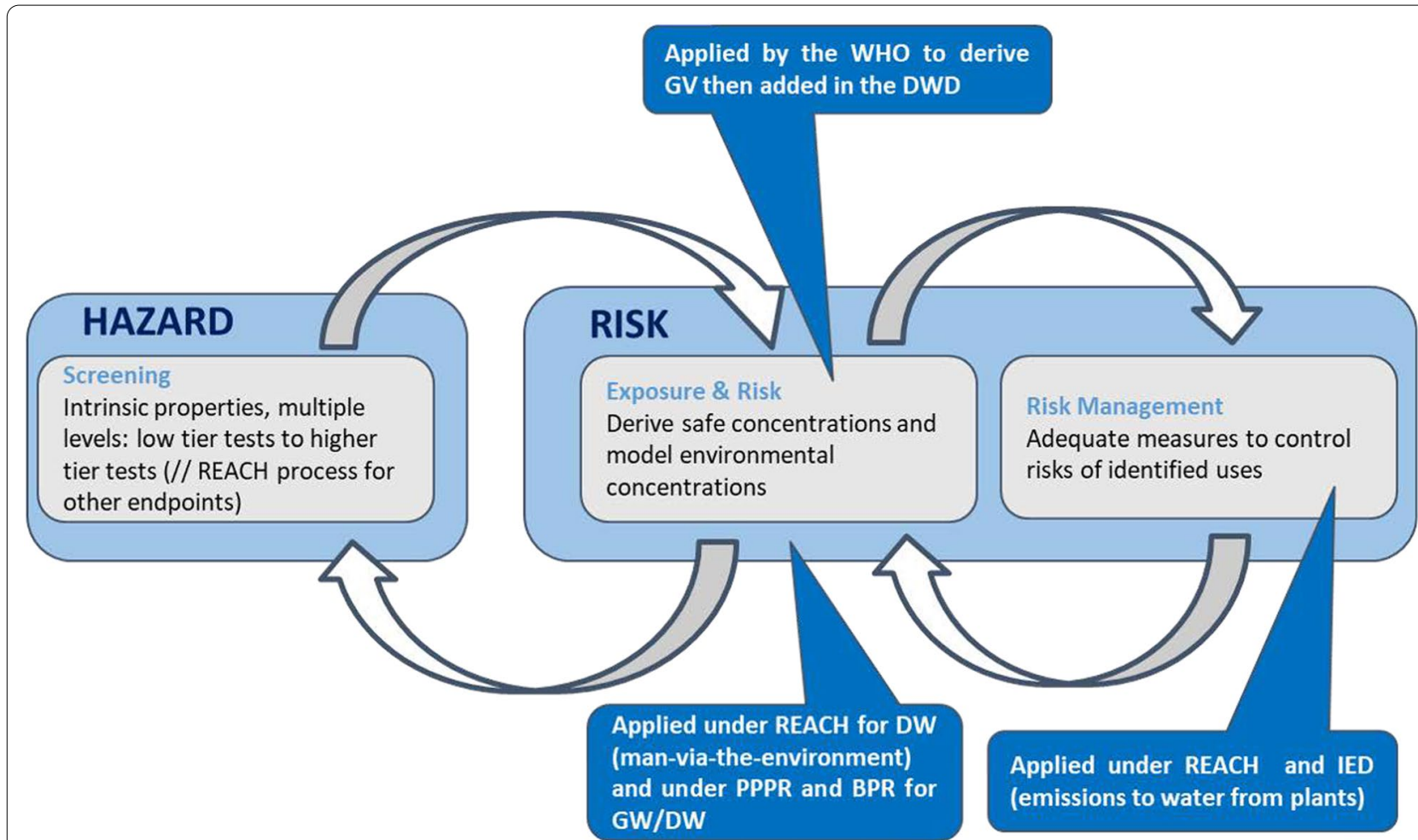

Fig. 7 Typical hazard assessment and risk assessment approach applied for chemical assessment today and their use in current legislative frameworks for drinking water and/or groundwater protection. DW drinking water, GW groundwater, DWD drinking water directive, GV guideline value, PPPR plant protection products regulation, BPR biocide products regulation, IED Industrial Emissions Directive

2022 in order to identify those as Substances of Very High Concern (SVHC),

- restrict all PFAS in a broad manner to ensure a PFAS phase out for "all but essential uses" by 2024 and

- define criteria for essential use drawing on the definition in the Montreal Protocol by 2022 (date to be confirmed).

To drive these changes, the EU will promote and reward production and use of safe and sustainable chemicals and incentivize innovation and substitution of substances of concern, as described below.

\section{CLP regulation}

As part of the revision of the CLP Regulation, the following new hazard classes have been proposed by the EU Commission: endocrine disruptors (EDs); $\mathrm{PBT}$ and $\mathrm{vPvB}$ substances; and, PMT and vPvM substances. From 2015, the CLP Regulation represents the only legal instrument in force for the classification and labelling of substances in the EU and as such has implications for other chemical legislations. By expanding the CLP Regulation, a more harmonized and higher level of protection from harmful chemicals for human health and the environment across a wide range of sectors (e.g. consumer products, waste, or industrial applications) can be achieved. This is being referred to as "one substance-one assessment". The implementation of new hazard classes in the CLP Regulation without prior implementation at the level of the Globally Harmonized System of Classification and Labelling of Chemicals (GHS) is an unusual step. Since the CLP Regulation is the legal instrument for the translation of GHS on the European level, changes are usually made in a "top down" manner. However, this approach could build the basis for modifications of GHS using a more "bottom up" approach.

Criteria for the more specific drafting of the new hazard classes are currently being discussed by the Competent Authorities for REACH and CLP (CARACAL), a group advising the EU Commission on questions related to REACH and CLP in close exchange with the respective experts, e.g. ECHAs PBT expert group. An adoption of the changes is expected in 2022.

\section{REACH regulation}

Similar to the changes of the CLP Regulation, adaptations of the REACH Regulation are part of a broad 
development of the EU's substance related and environmental regulations. Plans to adapt the legal text by amending Article 57 to include PMT and vPvM substances to be identified as SVHC aim to provide a higher level of protection. Currently, identifying PMT/vPvM substances as SVHC is only possible by demonstrating an equivalent level of concern to substances that are, for example, CMR or $\mathrm{PBT} / \mathrm{vPvB}$ substances. Other changes to the legal text shall ensure a stronger and more efficient enforcement by requiring dossier evaluations for all registrations (currently only required for a share of new registrations) and revising the authorization and restriction procedure.

Additionally, revisions of the Annexes of REACH are planned to better prioritize SVHC for (group) restrictions as well as to adapt the data requirements (i.e. what kind of information needs to be provided in the registration dossier) for EDs, and to restrict all "non-essential" uses of PFAS by adding the group to the list of restricted substances in Annex XVII.

\section{PFAS restriction}

The broad restriction of PFAS as a group is being led by Germany, the Netherlands, Denmark, Norway and Sweden. The restriction will cover all uses of PFAS and will aim to reduce regrettable substitution possibilities (such as when HFPO-DA replaced PFOA [100]). PFAS was recently defined as substances that contain at least one aliphatic carbon atom that is both saturated and fully fluorinated. This includes any chemical with at least one perfluorinated methyl group $\left(-\mathrm{CF}_{3}\right)$ or at least one perfluorinated methylene group $\left(-\mathrm{CF}_{2}-\right)$, including branched fluoroalkyl groups and substances containing ether linkages, fluoropolymers and side chain fluorinated polymers [101, 102]. More details about PFAS and their uses and environmental occurrence can be found in section "More details about PFAS and their uses and environmental occurrence" in the Additional file 1.

As the broad restriction process continues, there are several points that need special attention. The first is that there are only very few substances within the diverse PFAS class for which hazardous properties are known. For most of the substances in the group, no or only very little information is available. Nevertheless, the restriction proposal will demonstrate that a precautionary approach is needed for PFAS and that they should be regulated as a group even if data is lacking. Another important point is the availability of data related to aspects such as operational conditions or containment during manufacture and use or emissions during the whole service-life including end of life. Where specific information is missing, realistic worst-case scenarios will be used for release factors and emission calculations. In addition, information on the availability and feasibility of alternatives as well as the socio-economic impact of a PFAS ban needs to be considered.

The five authorities aim to submit the restriction proposal to the European Chemicals Agency (ECHA) in July 2022 [103]. It will then be assessed by ECHA's scientific committees RAC (Committee for risk assessment) and SEAC (Committee for socio-economic analysis). In parallel, a consultation on the proposal will provide a possibility to stakeholders to submit evidence and comments. The committees have to provide their scientific opinion on the proposal within 9 months (RAC) or 12 months (SEAC) after publication of the restriction dossier. After finalisation, the opinions of the committees together with the proposal and the comments received during the consultation will be submitted to the EU Commission for political decision-making. A decision by the EU Commission and entering into force of the restriction can be expected in 2024; given a transition period, the restriction could apply from 2025.

\section{Essential use}

The concept of essential use is applied in the Montreal Protocol, which outlines the global agreement on the phase-out of the production and use of ozone depleting substances [104]. However, it also allows parties to propose exemptions for certain substances and uses of that are considered essential at a national level. The two elements of an essential use under the Montreal Protocol are that a use is "necessary for health, safety or is critical for the functioning of society" and that "there are no available technically and economically feasible alternatives". Scientific discussion and debate around the essential use concept has increased since a paper was published in 2019 applying it to uses of PFAS [105]. Three use categories were defined: 1) "Non-essential uses" which are those driven by convenience and business opportunities and that are "nice to have" rather than having a function that is critical for health and safety, and the functioning of society, 2) "Substitutable uses", where the substance of concern does have a function necessary for health, safety or critical for the functioning of society, but its use is considered unnecessary because there are suitable alternatives available, and 3) "Essential uses" as described in the Montreal protocol.

Since this first publication, debate between scientists, regulators and chemical manufacturers has been ongoing and the most recent scientific paper published in 2021 [106] sets out to address common questions and possible misinterpretations of the essential use criteria. 
Questions such as "Who should apply the essential use concept?", "Is the essential use concept a threat to innovation or an opportunity?", "For which uses of which chemicals should the essential use concept be applied?" and "Which uses of chemicals are critical for the functioning of society?" are addressed. The authors go on to conclude that many of the challenges for the further implementation of the concept are not insurmountable. For instance, one important way to address many of these challenges is to innovate towards safe and sustainable alternatives to PFAS.

\section{Getting in control of PMT/vPvM substances through safe and sustainable by design strategies (H.P.H. Arp, A. Lennquist, N. Reineke, X. Trier)}

The ambitions in the Chemical Strategy for Sustainability Towards a Toxic Free Environment [15] call for a transition towards a new approach for how we use and assess substances. This new approach should increase the ability to generate goods in ways that minimize harm from chemicals along lifecycles of the chemicals and the products they are used in, and for the multiple aims of the EU Environmental Green Deal: Making chemicals safe towards human and environmental health, i.e. related to ecotoxicity, resource extraction and climate change. Such impacts along the lifecycles will have to be considered not just in the typical 5-10 years short term, but over the next $50-100$ years to protect future generations. This approach is referred to as Safe and Sustainable by Design (SSBD) in the Chemical Strategy for Sustainability Towards a Toxic Free Environment. Given the complexity of chemicals, and their (un)foreseen uses across multiple cycles of the materials, it is key to avoid the use of substances of concern, such as PMT/vPvM substances from the very beginning of the design phase [107]. The current approach where only substances classified as SVHC are avoided (or not even given authorisations) has not been sufficiently proactive to avoid pollution by e.g. PMT/ $\mathrm{vPvM}$ substances and their precursors. Therefore, it is very important that the identification and subsequent risk management of $\mathrm{PMT} / \mathrm{vPvM}$ substances is accelerated under current and future EU laws. In the SSBD approach, the design starts with a consideration of which service to provide [107]. To ensure as broad and open innovation space as possible, different types of expertise will have to be included in the process, from the industrial and environmental chemists, material designers, toxicologists, end-user experts, supply chain, marketing, economic and legal experts. This group will select a few design candidate substances not containing or foreseen to generate substances of concern, which will be assessed for impacts along their lifecycles. This requires some knowledge of the foreseen use of the design candidate substances. Crucial elements in such design would be how to fill data gaps for the design candidates, which models to use, the protection level to apply, and the criteria for assessing the overall impacts of a chemical, a material, a product or process. In the final scoring of the design candidates' minimum criteria need to be set so that the design candidates 'do no significant harm' on all the four parameters of safety to human and environmental health. A maximum score is set for each parameter, to allow to sum the scores without one score skewing the total score.

Another consideration might be if the chemicals in practice are likely to be kept inside the technosphere, also at their end of life during the separation and collection of the chemicals. Such considerations of whether a risk can be 'managed' are currently applied in risk assessments, e.g. under REACH. The concern is however that it is very difficult to foresee future uses of materials in a global recycling market, as well as assessing if the incidences of e.g. spills will increase with climate change, due to e.g. flooding of contaminated sites or storms and fires leading to accidents at industrial sites or even just overflow of waste water. In such an approach, substances without hazard properties or the most manageable hazard properties, as confirmed with the most assessment data possible, would be preferential design candidates. Therefore, there would be an increasing market for chemicals that are less risky, even if they accidentally are spilled in the environment - and therefore also for substances that are and form non-persistent, non-(eco)toxic substances, and which require low energy to synthesize and to manage though their supply chains. As another consequence this will call for less complex materials that do not require persistent, (eco)toxic substances to achieve their functionality, and which are possible to separate into clean materials during repair and recycling. The EU's Directorate-General for Research and Innovation (DG RTD) mapped all the SSBD and related methodologies in 2021 [107] and the EU's Joint Research Council is currently developing the SSBD criteria for DG RTD. European Commission activities on SSBD include funding of public-public research such as the Partnership for Assessment of Risks of Chemicals (PARC), public-private partnerships to start in 2022 and stakeholder meetings [108].

\section{Prioritizing substances for substitution}

As mentioned above, one important way to approach the SSBD strategy is to prioritize which substances should be replaced or avoided at the design stage. Databases and lists of harmful chemicals, such as the REACH SVHC list, addressing classes of chemicals known to be of concern 
(such as PFAS, phthalates, bisphenols, isocyanates, antimicrobials, organochlorines and organobromines [109]), or the Substitute It Now List (SIN List [110]) published by ChemSec provide good starting points to alert industry to which chemicals are needed to be replaced by safe and sustainable alternatives. Increasingly companies avoid using such classes of substances of concern in their procurement, both to protect their customers, the environment, and their business reputation and hence income (for example companies included in the ChemSec business group). The SIN List was launched in 2008 to provide guidance to industry on what substances to expect to be included in upcoming regulations. The SIN List uses the criteria for SVHC in REACH to list substances ahead of the official and much slower process to populate the Candidate SVHC List. This means that in addition to applying the existing criteria, the SIN List contains substances that are predicted (by ChemSec) to be targeted by regulations in the near future, based on an analysis of potential developments in chemical regulations. For instance, the SIN List has managed to both predict and influence the development of new regulations for endocrine disrupting chemicals. Some EDCs were added to the SIN List in 2011 and 2014, which in turn influenced their chemical management and policy discussion, ultimately culminating with their suggested inclusion as a new category for SVHCs in REACH, as well as a new hazard class. The 32 EDCs included in the SIN list were added on the basis of peer reviewed data and regulatory guidance documents. This list was used and referred to by companies, authorities, financial investors and others. The first EDC was added to the Candidate List in 2012, and since then more and more EDCs have been placed on the Candidate List, but at a slow pace. To date 19 chemicals have been placed on the Candidate List because of endocrine disrupting properties.

In 2019, 16 PMT substances were added to the SIN List after ChemSec realized that the most likely development of REACH would relate to the PMT/vPvM substance concept being developed at the time $[4,41]$. The initial PMT/vPvM substance list was narrowed down to 16 substances following in-depth scientific evaluations [111] and by considering substance uses in order to ensure that the listed substances were actually of relevance for companies. Since then, two of these 16 substances (PFBS and 1,4-dioxane) have been identified as SVHC based on their intrinsic properties and being regarded as posing an equivalent level of concern (ELoC) to $\mathrm{PBT} / \mathrm{vPvB}$ substances. In addition, 2,3,3,3-tetrafluoro2-(heptafluoropropoxy)propionic acid (HFPO-DA, also known as GenX) was identified as a SVHC due to PMT substance properties giving rise to an ELoC to $\mathrm{PBT} / \mathrm{vPvB}$ substances.

\section{Avoiding regrettable substitution}

When replacing substances of concern with sustainable chemicals as part of an SSBD strategy, there are several lessons that can be learned from previous unsuccessful attempts, so called "regrettable substitution" [112]. A well-known example of regrettable substitution was the substitution of the endocrine disrupting chemical bisphenol A with alternative bisphenols that were similarly harmful [113]. An example of burden shifting is found in the Montreal Protocol, where the substitution of refrigerants from ozone depleting chlorofluorocarbons (CFC) to hydrofluorocarbons (HFCs) was made, despite their very high global warming potential [114]. This led to amendments of the Montreal Protocol to reduce use of the most potent greenhouse cases, and hydrofluoroolefins (HFO). However, some HFCs and HFOs can degrade to the vPvM substance TFA discussed above, at yields of between 7 and 100\% [18]. The newest iteration of the Montreal Protocol, the Kigali Amendment, which is not yet ratified, seeks to phase out all hydrofluorocarbons; possible non-halogenated alternatives like $\mathrm{CO}_{2}$ and ammonia (see section "Additional details about avoiding regrettable substitution of refrigerants" in the Additional file 1 for more details). Both bisphenol A and the history of the Montreal protocol serve as examples of how important it is to avoid regrettable substitution and evaluate burden shifting of risks to other domains $[89,115]$.

Currently we are in a situation where there is a strong demand to move away from burning of fossil fuels that pollutes the atmosphere with greenhouse gases (such as $\mathrm{CO}_{2}$ and methane) to 'clean' renewable energy. While there is no doubt of the urgency of reducing GHG emissions, there is a risk that the replacement technologies contribute to pollution of freshwater resources. For instance, many are ionic liquids and molten salts, such as bis(trifluoromethane)sulfonimide is used as counter ions in lithium batteries. Both the substance itself as well as its degradation products such as $\mathrm{CF}_{3}-\mathrm{SO}_{2}-\mathrm{OH}$, are likely persistent and highly water mobile substances. Recent studies have detected $\mathrm{CF}_{3}-\mathrm{SO}_{2}-\mathrm{OH}$ widespread in German surface waters [18]. This risk is particularly high if the recovery of Lithium metals in batteries occurs under uncontrolled conditions in open systems by thermal recovery at smoldering temperatures of $300-500{ }^{\circ} \mathrm{C}$, where also the fluoropolymers PVDF and PTFE may form smaller PFAS degradation products. Since recovery systems for fluorinated polymers and such ionic liquids are not in place in the scale of the development of renewable energy technologies, there is a high risk of regrettable substitution replacing greenhouse gas pollution with human and ecotoxic chemical water pollution-particularly if recovery takes place outside of Europe where it is difficult to ensure controlled closed-loop systems. 
Based on these previous examples, the main challenge in alternatives assessment, is to identify better and safer solutions for problematic applications in the long term [116], following the safe and sustainable by design approach [107]. Even in cases where alternatives are available, the transition to SSBD requires much more. Enabling conditions such as policies (covering policies on products, and finance), education and technical support centres (to help industry to run SSBD and develop documentation of compliance) must be in place [107]. Education is of particular interest since it is related to changes in perceptions and values, which range as some of the most powerful elements in creating transitions. Not only will new technical skills be required, but process skills to run an interdisciplinary design process are needed. This is key to keep the innovation space open for providing services in various ways, including also by other business models that sell services rather than products.

\section{Conclusion}

Size of the gaps related to getting in control of PMT/vPvM substances (H. P H. Arp, S. E. Hale)

At the Third PMT/vPvM workshop where all of the information in this review was presented and discussed, the participants and attendees, consisting of regulators, researchers, chemical industry representatives, water producer representatives, and public safety NGOs, were invited to answer an online poll designed by the workshop organisers (consisting of this paper's co-authors: Sarah E Hale, Hans Peter H Arp, Michael Neumann, Ivo Schliebner and Jona Schulze). The poll consisted of 10 gaps related to getting in control of PMT/vPvM substances and the respondents were asked whether they thought the gap was wide, closing, or negligible [117]. A summary of the 120 respondents, presented in order of the size of the gap, from smallest to largest, is given below. It must be noted that this response rate is just 17\% of the peak audience numbers and the conclusions draw may not reflect the view of all workshop participants.

\section{Gap in chemical legislation}

Poll results: Wide gap (23\%); closing gap (63\%); negligible gap (14\%).

Chemical legislation was considered to have the smallest gap (ranked tenth), despite some short comings and difference of opinion of how well the WFD, the IED, the UWWTD, the Aarhus Convention and the Kyiv Protocol were protecting the environment from exposure to PMT/ vPvM substances. This small gap may have been reflective of the recently announced Chemicals Strategy for
Sustainability Towards a Toxic Free Environment [15], including its ambitious targets such as the PFAS restriction and incorporating PMT/vPvM in the CLP and REACH regulations, as discussed above. An important concern was related to the lack of harmonized approach that either unifies or explicitly accounts discrepancies in other European regulations or international regulations is accounted for, such as the potential discrepancy between the CLP regulation in Europe and the United Nations Global Harmonized System regulation.

\section{Gap in analytical methods}

Poll results: Wide gap (33\%); closing gap (57\%); negligible gap (10\%).

The gap in analytical methods being ranked second smallest is reflective of the recent advances in analytical methods presented above, as there are currently a great number of tools available for PMT/vPvM substance quantification. The main limitations to their use are practical, due to the small number of labs with the needed equipment, lack of reference standards for target analysis, and the difficulty in quantifying unknowns from non-target analysis. That said, the current regulatory and environmental and human health protection focus given to $\mathrm{PMT} / \mathrm{vPvM}$ substances may potentially drive further establishment of more accessible analytical methods for $\mathrm{PMT} / \mathrm{vPvM}$ substances in the coming years. Regarding reference standards, there is need for more examples of stewardship, such as that of the European Crop Protection Association who agreed to provide reference standards of pesticide transformation products that are not commercially available.

\section{Gap in risk assessment tools}

Poll results: Wide gap (34\%); closing gap (53\%); negligible gap (13\%).

The gap in risk assessment tools was ranked 8th, and this may be reflective of positive experiences with risk assessment models, such as the European union system for the evaluation of substances (EUSES) [118] and RIVM's SimpleTreat model for waste water treatment plants [119]. However, there are several substantial challenges for the development of risk assessment tools for industrial substances, such as accounting for a diverse array of emission scenarios [120], linking multi-media modelling with subsurface flow modelling (e.g. bank filtration) [84], and accounting for the complex sorption behaviour of mobility ionic and ionizable substances [121]. Currently there are research initiatives to improve risk assessments of persistent and mobile substances, (e.g. [122]), being driven by industrial stewardship (see Fig. 7) and other programs. 


\section{Gap in mobility data}

Poll results: Wide gap (37\%); closing gap (47\%); negligible gap (16\%).

The gap in mobility data, particularly $\log \mathrm{K}_{\mathrm{oc}}$, was ranked 7th and notably lower in comparison to the gaps in persistency data and toxicity data. An important concern related to the gap in mobility data is the complex nature of the sorption behaviour of ionic and ionizable substances [41, 83, 123]; $\mathrm{K}_{\mathrm{oc}}$ experiments or sorption experiments may be considered much easier than simulated half-life studies or a battery of toxicity tests, as indicated by the large number of substances with $\mathrm{K}_{\mathrm{oc}}$ values in the literature compared to half-lives [16]. It should be noted that the gap P, M and T data is linked to the gap in risk assessment models, as without detailed knowledge of half-lives, environmental pathways and toxicity, in addition to exposure pathways, it is challenging to accurately foresee risks.

\section{Gap in persistency data}

Poll results: Wide gap (41\%); closing gap (50\%); negligible gap (9\%).

The gap in measured half-life data (reflective of persistency), is known to be substantial, as this is so rarely quantified $[73,75]$ and thus this gap was ranked 6th. Persistency data is the biggest bottle neck to a PMT/vPvM substance evaluation, hence the need for methods like the OECD 309 test presented above. It is likely that this gap could be reduced by adjusting the regulatory definition of persistency, which is difficult based on the strong consensus around the current definition [124], or developing simpler methods or guidelines to infer environmental half-lives, which appears most practical.

\section{Gap in water remediation infrastructure}

Poll results: Wide gap (56\%); closing gap (31\%); negligible gap (13\%).

The gap in water infrastructure, ranked 5th, is a reflection on water remediation infrastructure varying geographically, from areas with advance treatment, to areas with only basic treatment [125]. This paper has shown that certain PMT/vPvM substances, like TFA, can only be removed using expensive, energy intensive processes like reverse osmosis or ion exchange resins. Upgrading equipment at water treatment plants would be not feasible in all geographic regions. End of pipe solutions should only be considered as complementary strategies for specific scenarios where the "polluter pays" principle may, to some extent, be applicable. Thus, substitution and avoidance of PMT/vPvM substance emission needs to be prioritized as the safer, cheaper, and more sustainable strategy to get in control of these substances. Nevertheless, advance remediation infrastructure can provide solutions in critical areas, particularly around points of highly concentrated chemical discharge.

\section{Gap in toxicity data}

Poll results: Wide gap (60\%); closing gap (30\%); negligible gap (10\%).

Though there is a lot of toxicity data required for chemical registration as part of the REACH regulation, this gap being ranked 4th important may be related to the lack of data for long-term chronic exposure to drinking water, and the time lag it has taken to recognize toxic mechanisms of many PFAS substances, after initial monitoring data have become available [85]. This was recently demonstrated when PFBS and 1,4-dioxane were identified as SVHC owing to their equivalent level of concern, as environmental monitoring data go back decades before the classifications of ecotoxic (PFBS) and carcinogenic (1,4 dioxane), respectively [10, 126, 127]. Another concern is mixture effects from the multiple, mostly unknown $\mathrm{PMT} / \mathrm{vPvM}$ substances and transformation products in drinking water, requiring the advancement of techniques like effect directed analysis to assess drinking water safety [128].

\section{Gap in safe and sustainable substitutes}

Poll results: Wide gap (60\%); closing gap (34\%); negligible gap $(6 \%)$.

The gap in safe and sustainable substances being ranked $3^{\text {rd }}$ largest is reflective of the newness and arguably complexity of this topic. SSBD represents a new approach that will require collaboration of various professionals including industrial designers, materials chemists, chemists, toxicologists/modellers, risk assessors, supply chain experts, marketing and retail experts. For instance, chemists could select feedstock/process/finishing chemicals, assess their characteristics and risks by modelling. Traditional synthetic chemistry must be weighed against biochemical synthesis, an appreciation of how the materials used can be recycled is needed and compliance method to test final products for substances of concern must be developed.

\section{Gap in monitoring data}

Poll results: Wide gap (64\%); closing gap (32\%); negligible gap (4\%).

The gap in monitoring data was considered as the second largest because most industries and regional regulators are not currently investing in screening programs for emerging PMT/vPvM substances, particularly outside of Western Europe. Even within Europe, monitoring for such substances has mainly been carried out by universities, research institutes and in some areas water producers. Analytical techniques are not the problem 
(as this was ranked the 9th), but the scarcity of monitoring occurring. One main reason for this is likely lack of regulatory pressure, as initial findings from scientists will often not spread into conventional monitoring programs without such regulatory guidance. Further, as the Swiss monitoring study highlighted here illustrated, there are several lines of evidence through non-target analysis that there are instances of pollution by unknown synthetic chemicals and their transformation products [50]; which leads us to the largest gap.

\section{Gap in the knowledge of substance mixtures and transformation products}

Poll results: Wide gap (91\%); closing gap (7\%); negligible gap $(2 \%)$.

The gap in the knowledge of substance mixtures and transformation products was ranked as the largest gap. Many REACH registered substances are "unknown or variable composition, complex reaction products" (referred to as UVCBs). Their substance composition is complex, but may contain several PMT/vPvM substances of concern. Further, it is often observed that many of the known transformation products of persistent substances are persistent substances that are also mobile $[12,129]$. There are also many unresolved signals from non-target screening approaches that could be transformation products, as presented with Swiss monitoring study above any database [50]. Smart suspect lists on PMT/vPvM substances including transformation products identified in studies by industry for the REACH registration process could be very beneficial for future comprehensive monitoring. Ideally, these lists should not only contain the compounds' names and properties but also link to open access spectra libraries where the MS spectra are available to support the identification process.

\section{Getting in control of PMT/vPvM substances through collaboration (H. P H. Arp, S. E. Hale)}

Getting in control of PMT/vPvM substances requires collaboration and dialogue between all stakeholders, even beyond the diverse set represented by the authors of this current review. Regulation and governance strategies would work best alongside industrial stewardship to best manage PMT/vPvM substances. SSBD tools require a collaboration of environmental scientists and toxicologists that conduct risk and alternatives assessment, based on the input from all designers, synthetic chemists, supply chain experts and material scientists concerned with the design of the product or service that is seeking to phase out PMT/vPvM substances. Market transition works best when there is a close dialogue with consumer advocate groups and regulatory mechanisms are in place to stimulate innovation away from harmful PMT/vPvM substances. Realising the goals set out in the Chemicals Strategy for Sustainability Towards a Toxic Free Environment will form an important basis for this cooperation towards zero pollution of PMT/vPvM substances.

\section{Methods}

The "Third PMT Workshop: Getting control of PMT and $\mathrm{vPvM}$ substances under REACH", took place on the 25th and 26th of March 2021 (online) and was attended by over 700 people. The audience and presenters consisted of scientists, chemical and water regulators, environment and health non-government organisations, and representatives from the chemical production and water services sectors, all concerned with protecting the quality of our water resources. Presentations were held about the knowledge gaps detailed above and attendees were invited to provide their opinions about the size of the knowledge gaps related to $\mathrm{PMT} / \mathrm{vPvM}$ substance research and regulation. The diverse perspectives from the presenters who make up the author group are presented herein to show new ideas of how PMT/vPvM substances can be brought under control in order to protect water resources, particularly those registered under REACH.

\section{Supplementary Information}

The online version contains supplementary material available at https://doi. org/10.1186/s12302-022-00604-4.

Additional file 1. Additional file consisting of figures, tables and text.

\section{Acknowledgements}

Karin Kiefer, Eawag, generated Additional file 1: Fig. S1.

\section{Authors' contributions}

SEH conceived the original article structure, co-developed the original draft, contributed to original writing and led revisions of the manuscript, ensuring all authors have approved the submitted article. HPA co-developed the original draft, contributed to original writing, co-revised the entire manuscript, and led the data analysis of polling results. All other authors wrote and revised the chapters for which they are explicitly named. All authors read and approved the final manuscript.

\section{Funding}

S.E. Hale and H.P.H. Arp acknowledge funding from the German Federal Ministry for the Environment, Nature Conservation, Building and Nuclear Safety (FKZ3719654080)

Availability of data and materials

The datasets used and/or analysed during the current study are available from the corresponding author on reasonable request. 


\section{Declarations}

Ethics approval and consent to participate

Not applicable.

\section{Consent for publication}

Not applicable.

\section{Competing interests}

The views of the authors do not necessarily reflect the views of the German Environment Agency (UBA). All authors declare that they have no conflicting interests.

\begin{abstract}
Author details
${ }^{1}$ Norwegian Geotechnical Institute (NGI), Ullevål Stadion, P.O. Box 3930, 0806 Oslo, Norway. ${ }^{2}$ German Environment Agency, Section IV 2.3 Chemicals, Wörlitzer Platz 1, 06844 Dessau-Roßlau, Germany. ${ }^{3}$ Federal Institute for Occupational Safety and Health (BAuA), Division 5 Federal Office for Chemicals, Friedrich-Henkel-Weg 1-25, 44149 Dortmund, Germany. ${ }^{4}$ EurEau European Federation of National Associations of Water Services, Rue du Luxembourg 47-51, 1050 Brussels, Belgium. ${ }^{5}$ Solvay Sa, Rue de Ransbeek 310, B-1120 Brussels, Belgium. ${ }^{6}$ European Chemical Industry Council - Cefic Aisbl, Rue Belliard 40, b15, 1040 Brussels, Belgium. ${ }^{7}$ National Institute for Public Health and the Environment (RIVM), P.O. Box 1, 3720 BA Bilthoven, The Netherlands. ${ }^{8}$ Delft University of Technology, P.O. Box 5048, 2600 GA Delft, The Netherlands. ${ }^{9}$ KWR Water Research Institute and Wageningen University and Research, Nieuwegein, The Netherlands. ${ }^{10}$ Swiss Federal Institute of Aquatic Science and Technology, 8600 Dübendorf, Switzerland. ${ }^{11}$ Institute of Biogeochemistry and Pollutant Dynamics, ETH Zurich, 8092 Zurich, Switzerland. ${ }^{12}$ Vitens N.V., Afdeling Klantenservice, Postbus 2014, 6802 CA Arnhem, The Netherlands. ${ }^{13}$ German Chemical Industry Association (VCI), Mainzer Landstrasse 55, 60329 Frankfurt, Germany. ${ }^{14}$ International Chemical Secretariat, ChemSec. Första Långgatan 18, S-413 28 Göteborg, Sweden. ${ }^{15}$ AFIN-TS GmbH (Analytisches Forschungs(Research)Institut Für Non-Target Screening), Am Mittleren Moos 48, 86167 Augsburg, Germany. ${ }^{16} \mathrm{TZW}$ : DVGW-Technologiezentrum Wasser, Karlsruher Straße 84, 76139 Karlsruhe, Germany. ${ }^{17}$ Department of Product Safety, BASF SE, GBP/RA, Z 570, 67056 Ludwigshafen, Germany. ${ }^{18}$ CHEM Trust Europe, Hudtwalcker Str 31 a, 22299 Hamburg, Germany. ${ }^{19}$ Environmental Geosciences EDGE, Centre for Microbiology and Environmental Systems Science, University of Vienna, Vienna, Austria. ${ }^{20}$ Vewin, Association of Dutch Water Companies, P.O box 90611, 2509 LP The Hague, The Netherlands. ${ }^{21} 2720$ Copenhagen, Denmark. ${ }^{22}$ Department of Chemistry, Norwegian University of Science and Technology (NTNU), N-7491 Vanløse, Norway.
\end{abstract}

Received: 9 December 2021 Accepted: 24 February 2022

Published online: 08 March 2022

\section{References}

1. Mostert E (2009) International co-operation on Rhine water quality 1945-2008: an example to follow? Phys Chem Earth 34:142-149. https://doi.org/10.1016/J.PCE.2008.06.007

2. Wang Z, Walker GW, Muir DCG, Nagatani-Yoshida K (2020) Toward a global understanding of chemical pollution: a first comprehensive analysis of national and regional chemical inventories. Environ Sci Technol 54:2575-2584

3. Munthe J, Lexén J, Skårman T, Posthuma L, Brack W, Altenburger R, Brorström-Lundén E, Bunke D, Faust M, Rahmberg M et al (2019) Increase coherence, cooperation and cross-compliance of regulations on chemicals and water quality. Environ Sci Eur. https://doi.org/10. 1186/S12302-019-0235-8

4. Neumann, M.; Schliebner, I. Protecting the sources of our drinking water: The criteria for identifying persistent, mobile and toxic (PMT) substances and very persistent and very mobile (VPVM) substances under EU Regulation REACH (EC) No 1907/2006. UBA TEXTE 127/2019. Ger. Environ. Agency (UBA), Dessau-Roßlau, Ger. ISBN 1862-4804. 87 pages 2019. https://www.umweltbundesamt.de/sites/default/files/ medien/1410/publikationen/2019-11-29_texte_127-2019_protectingsources-drinking-water-pmt.pdf
5. Rockström J, Steffen W, Noone K, Persson Å, Chapin FS, Lambin EF, Lenton TM, Scheffer M, Folke C, Schellnhuber HJ et al (2009) A safe operating space for humanity. Nature. https://doi.org/10.1038/461472a

6. Chen R, Li G, He Y, Pan L, Yu Y, Shi B (2021) Field study on the transportation characteristics of PFASs from water source to tap water. Water Res 198:117162. https://doi.org/10.1016/J.WATRES.2021.117162

7. Hu XC, Andrews DQ, Lindstrom AB, Bruton TA, Schaider LA, Grandjean P, Lohmann R, Carignan CC, Blum A, Balan SA et al (2016) Detection of poly- and perfluoroalkyl substances (PFASs) in U.S. drinking water linked to industrial sites, military fire training areas, and wastewater treatment plants. Environ Sci Technol Lett 3:344-350. https://doi.org/10.1021/ACS. ESTLETT.6B00260

8. Stoiber T, Evans S, Naidenko OV (2020) Disposal of products and materials containing per- and polyfluoroalkyl substances (PFAS): a cyclical problem. Chemosphere 260:127659. https://doi.org/10.1016/J.CHEMO SPHERE.2020.127659

9. Hale SE, Arp HPH, Schliebner I, Neumann M (2020) What's in a name: persistent, mobile, and toxic (PMT) and very persistent and very mobile (vPvM) substances. Environ Sci Technol 54:14790-14792. https://doi. org/10.1021/ACS.EST.0C05257

10. Hale SE, Arp HPH, Schliebner I, Neumann M (2020) Persistent, mobile and toxic (PMT) and very persistent and very mobile (vPvM) substances pose an equivalent level of concern to persistent, bioaccumulative and toxic (PBT) and very persistent and very bioaccumulative (VPvB) substances under REACH. Environ Sci Eur 32:1-15

11. Rüdel H, Körner W, Letzel T, Neumann M, Nödler K, Reemtsma T (2020) Persistent, mobile and toxic substances in the environment: a spotlight on current research and regulatory activities. Environ Sci Eur. https:// doi.org/10.1186/S12302-019-0286-X

12. Arp HPH, Brown TN, Berger U, Hale SE (2017) Ranking REACH registered neutral, ionizable and ionic organic chemicals based on their aquatic persistency and mobility. Environ Sci Process Impacts 19:939-955. https://doi.org/10.1039/c7em00158d

13. Reemtsma T, Berger U, Arp HPH, Gallard H, Knepper TP, Neumann M, Quintana JB, Voogt PD (2016) Mind the gap: persistent and mobile organic compounds-water contaminants that slip through. Environ Sci Technol. https://doi.org/10.1021/acs.est.6b03338

14. Reemtsma T, Berger U, Arp HPH, Gallard H, Knepper TP, Neumann M, Quintana JB, De VP (2016) Mind the gap: persistent and mobile organic compounds-water contaminants that slip through. Environ Sci Technol 50:10308-10315. https://doi.org/10.1021/acs.est.6b03338

15. EC. Chemicals strategy for sustainability towards a toxic-free environment; 2020; https://ec.europa.eu/environment/pdf/chemicals/2020/ 10/Strategy.pdf

16. Arp, H.P.H.; Hale, S. REACH: Improvement of guidance and methods for the identification and assessment of PMT/VPVM substances. UBA texte 126/2019. 2019, 1-129. https://www.umweltbundesamt.de/sites/defau It/files/medien/1410/publikationen/2019-11-29_texte_126-2019_ reach-pmt.pdf

17. Scheurer M, Nödler K, Freeling F, Janda J, Happel O, Riegel M, Müller U, Storck FR, Fleig M, Lange FT et al (2017) Small, mobile, persistent: trifluoroacetate in the water cycle-overlooked sources, pathways, and consequences for drinking water supply. Water Res 126:460-471. https://doi.org/10.1016/J.WATRES.2017.09.045

18. Behringer, D.; Heydel, F.; Gschrey, B.; Osterheld, S.; Schwarz, W.; Warncke, K.; Freeling, F.; Nödler, K.; Wasser, T.; Henne, S.; et al. Persistent degradation products of halogenated refrigerants and blowing agents in the environment: type, environmental concentrations, and fate with particular regard to new halogenated substitutes with low global warming potential. UBA texte 73/2021 2021. https://www.umweltbundesamt. de/sites/default/files/medien/5750/publikationen/2021-05-06_texte_ 73-2021_persistent_degradation_products.pdf

19. Solomon K, Velders G, Wilson S, Madronich S, Longstreth J, Aucamp P, Bornman J (2016) Sources, fates, toxicity, and risks of trifluoroacetic acid and its salts: Relevance to substances regulated under the Montreal and Kyoto Protocols. J Toxicol Environ Health B Crit Rev 19:289-304. https://doi.org/10.1080/10937404.2016.1175981

20. Tisler S, Zindler F, Freeling F, Nödler K, Toelgyesi L, Braunbeck T, Zwiener C (2019) Transformation products of fluoxetine formed by photodegradation in water and biodegradation in zebrafish embryos (Danio rerio). 
Environ Sci Technol 53:7400-7409. https://doi.org/10.1021/ACS.EST. 9B00789

21. EURL-SRM Residue Findings Report - Residues of DFA and TFA in Samples of Plant Origin. EurlSrm_residue-Observation_TFA-DFA (eurlpesticides.eu). 2017, Accessed 29 Jun 2021.

22. Scheurer M, Nödler K (2021) Ultrashort-chain perfluoroalkyl substance trifluoroacetate (TFA) in beer and tea-an unintended aqueous extraction. Food Chem 351:129304. https://doi.org/10.1016/J.FOODCHEM. 2021.129304

23. Duan Y, Sun H, Yao Y, Meng Y, Li Y (2020) Distribution of novel and legacy per-/polyfluoroalkyl substances in serum and its associations with two glycemic biomarkers among Chinese adult men and women with normal blood glucose levels. Environ Int 134:105295. https://doi. org/10.1016/J.ENVINT.2019.105295

24. Pickard HM, Criscitiello AS, Persaud D, Spencer C, Muir DCG, Lehnherr I, Sharp MJ, Silva AO (2020) Ice core record of persistent short-chain fluorinated alkyl acids: evidence of the impact from global environmental regulations. Geophys Res Lett. https://doi.org/10.1029/2020GL0875 35

25. Freeling F, Behringer D, Heydel F, Scheurer M, Ternes TA, Nödler K (2020) Trifluoroacetate in precipitation: deriving a benchmark data set. Environ Sci Technol 54:11210-11219. https://doi.org/10.1021/ACS.EST.0C02910

26. Berends AG, Boutonnet JC, De Rooij CG, Thompson RS (1999) Toxicity of trifluoroacetate to aquatic organisms. Environ Toxicol Chem 18:10531059. https://doi.org/10.1002/ETC.5620180533

27. Seiber, J.N. and Cahill, T.M. Pesticides, organic contaminants, and pathogens in air-chemodynamics, health effects, sampling, and analysis.; irst editi.; 2022;

28. Stepien DK, Diehl P, Helm J, Thoms A, Püttmann W (2014) Fate of 1,4-dioxane in the aquatic environment: from sewage to drinking water. Water Res 48:406-419. https://doi.org/10.1016/J.WATRES.2013.09. 057

29. Carrera G, Vegué L, Boleda MR, Ventura F (2017) Simultaneous determination of the potential carcinogen 1,4-dioxane and malodorous alkyl1,3-dioxanes and alkyl-1,3-dioxolanes in environmental waters by solidphase extraction and gas chromatography tandem mass spectrometry. J Chromatogr A 1487:1-13. https://doi.org/10.1016/J.CHROMA.2017.01. 015

30. OVAM Additives of chlorinated solvents-1,4-dioxane in Flanders. 2017 https://www.ovam.be/sites/default/files/atoms/files/Rapport\%20\% 28E\%29\%20-\%20Additives\%20of\%20chlorinated\%20solvents\%20-\% 201\%2C4-dioxine\%20in\%20Flanders.pdf

31. Abe A (1999) Distribution of 1, 4-dioxane in relation to possible sources in the water environment. Sci Total Environ 227:41-47. https://doi.org/ 10.1016/50048-9697(99)00003-0

32. Anderson RH, Anderson JK, Bower PA (2012) Co-occurrence of 1,4-dioxane with trichloroethylene in chlorinated solvent groundwater plumes at US Air Force installations: Fact or fiction. Integr Environ Assess Manag 8:731-737. https://doi.org/10.1002/IEAM.1306

33. Adamson DT, Mahendra S, Walker KL, J., Rauch, S.R., Sengupta, S., Newell, C.J. (2014) A multisite survey to identify the scale of the 1,4-dioxane problem at contaminated groundwater sites. Environ Sci Technol Lett 1:254-258. https://doi.org/10.1021/EZ500092U

34. Karges U, Becker J, Püttmann W (2018) 1, 4-Dioxane pollution at contaminated groundwater sites in western Germany and its distribution within a TCE plume. Sci Total Environ 619-620:712-720. https://doi.org/ 10.1016/j.scitotenv.2017.11.043

35. Adamson DT, Piña EA, Cartwright AE, Rauch SR, Anderson RH, Mohr T, Connor JA (2017) 1, 4-Dioxane drinking water occurrence data from the third unregulated contaminant monitoring rule. Sci Total Environ 596-597:236-245. https://doi.org/10.1016/j.scitotenv.2017.04.085

36. Carrera G, Vegué L, Ventura F, Hernández-Valencia A, Devesa R, Boleda M (2019) Dioxanes and dioxolanes in source waters: occurrence, odor thresholds and behavior through upgraded conventional and advanced processes in a drinking water treatment plant. Water Res 156:404-413. https://doi.org/10.1016/J.WATRES.2019.03.026

37. da Silva MLB, He Y, Mathieu J, Alvarez PJJ (2020) Enhanced long-term attenuation of 1,4-dioxane in bioaugmented flow-through aquifer columns. Biodegradation 31:201-211. https://doi.org/10.1007/ S10532-020-09903-0
38. Li M, Van Orden ET, DeVries DJ, Xiong Z, Hinchee R, Alvarez PJ (2015) Bench-scale biodegradation tests to assess natural attenuation potential of 1,4-dioxane at three sites in California. Biodegradation 26:39-50. https://doi.org/10.1007/S10532-014-9714-1

39. Stepien DK, Diehl P, Helm J, Thoms A (2013) Fate of 1,4-dioxane in the aquatic environment : from sewage to drinking water. Water Res. https://doi.org/10.1016/j.watres.2013.09.057

40. ECHA. European Chemicals Agency Inclusion of substances of very high concern in the Candidate List for eventual inclusion in Annex XIV, (Decision of the European Chemicals Agency), D(2021)4569-DC_19622. 2021. https://echa.europa.eu/documents/10162/ab77aafb-7b98-5cbb3416-fc28e393a48e

41. Arp, H.P.H.; Hale, S.E. REACH: Improvement of guidance methods for the identification and evaluation of PM/PMT substances. UBA TEXTE 126/2019. German Environment Agency (UBA), Dessau-Roßlau, Germany. ISBN: 1862-4804. 130 pages. https://www.umweltbundesamt. de/en/publikationen/reach-improvement-of-guidance-methods-forthe. Accessed 3 Mar 2022

42. Neuwald I, Muschket M, Zahn D, Berger U, Seiwert B, Meier T, Kuckelkorn J, Strobel C, Knepper TP, Reemtsma T (2021) Filling the knowledge gap: a suspect screening study for 1310 potentially persistent and mobile chemicals with SFC- and HILIC-HRMS in two German river systems. Water Res. https://doi.org/10.1016/J.WATRES.2021.117645

43. Smith CA, Want EJ, O'Maille G, Abagyan R, Siuzdak G (2006) XCMS: Processing mass spectrometry data for metabolite profiling using nonlinear peak alignment, matching, and identification. Anal Chem 78:779-787. https://doi.org/10.1021/AC051437Y

44. Pluskal T, Castillo S, Villar-Briones A, Orešič M (2010) MZmine 2: Modular framework for processing, visualizing, and analyzing mass spectrometry-based molecular profile data. BMC Bioinforma 11:1-11. https://doi. org/10.1186/1471-2105-11-395

45. Minkus S, Grosse S, Bieber S, Veloutsou S, Letzel T (2020) Optimized hidden target screening for very polar molecules in surface waters including a compound database inquiry. Anal Bioanal Chem 412:4953-4966. https://doi.org/10.1007/S00216-020-02743-0

46. Helmus R, ter Laak TL, van Wezel AP, de Voogt P, Schymanski EL (2021) patRoon: open source software platform for environmental mass spectrometry based non-target screening. J Cheminformatics 13:1-25. https://doi.org/10.1186/S13321-020-00477-W

47. Minkus S, Bieber S, Letzel T (2021) (Very) polar organic compounds in the Danube river basin: A non-target screening workflow and prioritization strategy for extracting highly confident features. Anal Methods 13:2044-2054. https://doi.org/10.1039/D1AY00434D

48. Bieber, S.; Letzel, T. White paper-polarity-extended chromatography, AFIN-TS Forum. 2020, February 1-4. https://afin-ts.de/wp-content/ uploads/2020/04/AFIN-TS_01_2020_Pol_Ex.pdf

49. Bieber S, Greco G, Grosse S, Letzel T (2017) RPLC-HILIC and SFC with mass spectrometry: polarity-extended organic molecule screening in environmental (Water) samples. Anal Chem 89:7907-7914. https://doi. org/10.1021/ACS.ANALCHEM.7B00859

50. Kiefer K, Du L, Singer H, Hollender J (2021) Identification of LC-HRMS nontarget signals in groundwater after source related prioritization. Water Res, https://doi.org/10.1016/JWATRES 2021.116994

51. Mechelke J, Longrée P, Singer H, Hollender J (2019) Vacuum-assisted evaporative concentration combined with LC-HRMS/MS for ultra-tracelevel screening of organic micropollutants in environmental water samples. Anal Bioanal Chem. https://doi.org/10.1007/S00216-019-01696-3

52. Köke N, Zahn D, Knepper TP, Frömel T (2018) Multi-layer solid-phase extraction and evaporation -enrichment methods for polar organic chemicals from aqueous matrices. Anal Bioanal Chem 410:2403-2411. https://doi.org/10.1007/S00216-018-0921-1

53. Kern S, Fenner K, Singer HP, Schwarzenbach RP, Hollender J (2009) Identification of transformation products of organic contaminants in natural waters by computer-aided prediction and high-resolution mass spectrometry. Environ Sci Technol 43:7039-7046. https://doi.org/10 1021/ES901979H

54. Reemtsma T, Alder L, Banasiak U (2013) A multimethod for the determination of 150 pesticide metabolites in surface water and groundwater using direct injection liquid chromatography-mass spectrometry. J Chromatogr A 1271:95-104. https://doi.org/10.1016/J.CHROMA.2012. 11.023 
55. Crop life Europe. https://croplifeeurope.eu/pre-market-resources/analy tical-standards-reference-standard-compounds-for-water-monitoringprogrammes/. Accessed 3 Mar 2022.

56. Hollender J, Schymanski EL, Singer HP, Ferguson PL (2017) Nontarget screening with high resolution mass spectrometry in the environment: ready to go? Environ Sci Technol 51:11505-11512. https://doi.org/10. 1021/ACS.EST.7B02184

57. Schulze S, Zahn D, Montes R, Rodil R, Quintana JB, Knepper TP, Reemtsma T, Berger U (2019) Occurrence of emerging persistent and mobile organic contaminants in European water samples. Water Res 153:80-90. https://doi.org/10.1016/J.WATRES.2019.01.008

58. Zektser, I.S. and Everett, L.G. Groundwater resources of the world and their use, United Nations Educational, Scientific and Cultural Organization, Paris. 2004. https://www.un-igrac.org/sites/default/files/resources/ files/Groundwater_around_world.pdf

59. Lapworth DJ, Baran N, Stuart ME, Ward RS (2012) Emerging organic contaminants in groundwater: A review of sources, fate and occurrence. Environ Pollut 163:287-303. https://doi.org/10.1016/J.ENVPOL.2011.12. 034

60. Sjerps RMA, Brunner AM, Fujita Y, Bajema B, de Jonge $M$, Bäuerlein PS, de Munk J, Schriks M, van Wezel A (2021) Clustering and prioritization to design a risk-based monitoring program in groundwater sources for drinking water. Environ Sci Eur. https://doi.org/10.1186/ S12302-021-00470-6

61. ECHA. European chemicals agency guidance on information requirements and chemical safety assessment chapter R.11: PBT/VPvB assessment Version 3.0. ECHA-17-G-12-EN. 2017. https://echa.europa. eu/documents/10162/17224/information_requirements_r11_en.pdf/ a8cce23f-a65a-46d2-ac68-92fee1f9e54f

62. Kalmykova Y, Björklund K, Strömvall AM, Blom L (2013) Partitioning of polycyclic aromatic hydrocarbons, alkylphenols, bisphenol $\mathrm{A}$ and phthalates in landfill leachates and stormwater. Water Res 47:13171328. https://doi.org/10.1016/J.WATRES.2012.11.054

63. Bansal RC, Goyal M (2005) Activated carbon. Adsorption. https://doi. org/10.1201/9781420028812

64. Zhu D, Pignatello JJ (2005) Characterization of aromatic compound sorptive interactions with black carbon (charcoal) assisted by graphite as a model. Environ Sci Technol 39:2033-2041. https://doi.org/10.1021/ es0491376

65. Sigmund G, Gharasoo M, Hüffer T, Hofmann T (2020) Deep learning neural network approach for predicting the sorption of ionizable and polar organic pollutants to a wide range of carbonaceous materials. Environ Sci Technol 54:4583-4591. https://doi.org/10.1021/ACS.EST. 9B06287

66. Kah M, Sigmund G, Xiao F, Hofmann T (2017) Sorption of ionizable and ionic organic compounds to biochar, activated carbon and other carbonaceous materials. Water Res 124:673-692. https://doi.org/10.1016/j. watres.2017.07.070

67. Hagemann N, Schmidt HP, Kägi R, Böhler M, Sigmund G, Maccagnan A, McArdell CS, Bucheli TD (2020) Wood-based activated biochar to eliminate organic micropollutants from biologically treated wastewater. Sci Total Environ 730:138417. https://doi.org/10.1016/J.SCITOTENV.2020. 138417

68. Gagliano E, Sgroi M, Falciglia PP, Vagliasindi FGA, Roccaro P (2020) Removal of poly- and perfluoroalkyl substances (PFAS) from water by adsorption: role of PFAS chain length, effect of organic matter and challenges in adsorbent regeneration. Water Res 171:115381. https://doi. org/10.1016/J.WATRES.2019.115381

69. Albergamo V, Blankert B, Cornelissen ER, Hofs B, Knibbe W-J, van der Meer W, de Voogt P (2019) Removal of polar organic micropollutants by pilot-scale reverse osmosis drinking water treatment. Water Res 148:535-545

70. United States Environmental Protection Agency Emerging technologies for wastewater treatment and in-plant wet weather management. EPA832-R-12-011. 2013. https://www.epa.gov/sites/default/files/2019-02/ documents/emerging-tech-wastewater-treatment-management.pdf

71. Brunner AM, Bertelkamp C, Dingemans MML, Kolkman A, Wols B, Harmsen D, Siegers W, Martijn BJ, Oorthuizen WA, ter Laak TL (2020) Integration of target analyses, non-target screening and effect-based monitoring to assess OMP related water quality changes in drinking water treatment. Sci Total Environ 705:135779. https://doi.org/10. 1016/J.SCITOTENV.2019.135779

72. European Commission Directive 2000/60/EC of the European Parliament and of the Council of 23 October 2000 establishing a framework for Community action in the field of water policy. Official Journal L 327 , 22/12/2000 p. 1-73. 2000. https://eur-lex.europa.eu/legal-content/en/ TXT/?uri=CELEX:32000L0060

73. United Nations Environment Programme UNEP UNEP Yearbook: Emerging issues in our Global Environment; 2013. https://wedocs.unep.org/ handle/20.500.11822/8222

74. OECD 309: Aerobic Mineralisation in Surface Water-Simulation Biodegradation Test. OECD Guidelines for the Testing of Chemicals, Section, 3. 2004. https://www.oecd-ilibrary.org/environment/test-no-309-aerobicmineralisation-in-surface-water-simulation-biodegradation-test_97892 64070547-en

75. Hofman-Caris, Roberta, Claßen, D. Persistence of gabapentin, $1 \mathrm{Hbenzo-}$ triazole, diglyme, DTPA, 1,4- dioxane, melamine and urotropin in surface water: Testing of chemicals according to the OECD 309 guideline. 2020. https://edepot.wur.nl/539038

76. Gustafson D (1989) Groundwater ubiquity score-a simple method for assessing pesticide leachability. Environ Toxicol Chem 8:339

77. ECHA European Chemicals Agency Guidance on the Biocidal Products Regulation Volume IV: Environment Part A: Information Requirements. 2018, https://doi.org/10.2823/49865.

78. European Commission Ad Hoc Meeting of CARACAL PBT/VPvB/PMT/ vPvM criteria 30 September 2021. Topic: Discussion on PMT/vPVM possible criteria in CLP. Ad-hoc CA/03/2021. 9 pp. Brussels. 2021.

79. Bronner G, Goss KU (2011) Sorption of organic chemicals to soil organic matter: Influence of soil variability and ph dependence. Environ Sci Technol 45:1307-1312. https://doi.org/10.1021/es102576e

80. Helling CS, Chesters G, Corey RB (1964) contribution of organic matter and clay to soil cation- exchange capacity as affected by the $\mathrm{pH}$ of the saturating solution. Soil Sci Soc Am J. https://doi.org/10.2136/sssaj1964. 03615995002800040020x

81. Henneberger L, Goss K-U (2019) Environmental sorption behavior of ionic and ionizable organic chemicals. Rev Environ Contam Toxicol 253:43-64. https://doi.org/10.1007/398_2019_37

82. Zareitalabad P, Siemens J, Hamer M, Amelung W (2013) Perfluorooctanoic acid (PFOA) and perfluorooctanesulfonic acid (PFOS) in surface waters, sediments, soils and wastewater-a review on concentrations and distribution coefficients. Chemosphere 91:725-732. https://doi. org/10.1016/j.chemosphere.2013.02.024

83. Droge STJ, Goss KU (2013) Development and evaluation of a new sorption model for organic cations in soil: Contributions from organic matter and clay minerals. Environ Sci Technol 47:14233-14241. https:// doi.org/10.1021/es4031886

84. ECETOC Technical report 139: Persistent chemicals and water resources protection. 2021. https://www.ecetoc.org/wp-content/uploads/2021/ 05/ECETOC-TR-139-Persistent-chemicals-and-water-resources-prote ction-2.pdf

85. Cousins IT, Ng CA, Wang Z, Scheringer M (2019) Why is high persistence alone a major cause of concern? Environ Sci Process Impacts 21:781-792. https://doi.org/10.1039/c8em00515j

86. Kalberlah, F.; Oltmanns, J.; Schwarz, M.; Baumeister, J.; Striffler, A. Guidance for the precautionary protection of raw water destined for drinking water extraction from contaminants regulated under REACH. UFOPLAN Project FKZ 371265416. German Federal Environmental Agency. 2014. https://www.fachoekotoxikologie.de/fileadmin/facho ekotoxikologie/abgeschlossene_Arbeiten/2016/2_FKZ_371265416_ UBA_REPORT-PMT_final-FoBiG.pdf

87. Holmberg, R.; Bay Wedebye, E.; Georgiev Nikolov, Nikolai Tyle, H. How many potential vPVM/PMT substances have been registered under REACH? - vPVM/PMT-screening by using the Danish (Q)SAR database Welcome to DTU Research Database Available online: https://orbit.dtu. dk/en/publications/how-many-potential-vpvmpmt-substances-havebeen-registered-under. Accessed 11 Sep 2021.

88. Bronner G, Goss K-U (2011) Predicting sorption of pesticides and other multifunctional organic chemicals to soil organic carbon. Environ Sci Technol 45:1313-1319. https://doi.org/10.1021/es102553y

89. Zheng Z, Peters GM, Arp HPH, Andersson PL (2019) Combining in silico tools with multicriteria analysis for alternatives assessment of hazardous 
chemicals: a case study of decabromodiphenyl ether alternatives. Environ Sci Technol. https://doi.org/10.1021/acs.est.8b07163

90. European Commission DIRECTIVE (EU). 2020/2184 of the European parliament and of the council of 16 December 2020 on the quality of water intended for human consumption (recast). 2020,

91. PronkTE, Hofman-Caris RCHM, Vries D, Kools SAE, ter Laak TL, Stroomberg GJ (2021) A water quality index for the removal requirement and purification treatment effort of micropollutants. Water Supply 21:128-145. https://doi.org/10.2166/WS.2020.289

92. Timmer, H.; Bannink, A. "Combining science and legislation to protect the surface water sources of our drinking water", Presentation: The Third PMT Workshop. Berlin. 2021. https://www.umweltbundesamt.de/sites/ default/files/medien/3521/dokumente/day_2_afternoon_04_harrie_ timmer_c. Accessed 3 Mar 2022.

93. Carvalho L, Mackay EB, Cardoso AC, Baattrup-Pedersen A, Birk S, Blackstock KL, Borics G, Borja A, Feld CK, Ferreira MT et al (2019) Protecting and restoring Europe's waters: an analysis of the future development needs of the Water Framework Directive. Sci Total Environ 658:12281238. https://doi.org/10.1016/J.SCITOTENV.2018.12.255

94. Wuijts, S.; Zijp, C.; Reijnders, R. Drinking water in river basin management plans of EU Member States in the Rhine and Meuse river basins Drinking water in river basin management plans of EU Member States in the Rhine and Meuse river basins. 2010. https://www.rivm.nl/bibli otheek/rapporten/734301035.pdf

95. Pistocchi A, Dorati C, Aloe A, Ginebreda A, Marcé R (2019) River pollution by priority chemical substances under the Water Framework Directive: a provisional pan-European assessment. Sci Total Environ 662:434-445. https://doi.org/10.1016/J.SCITOTENV.2018.12.354

96. Caspari, M., Goppel, M. Development of water quality in the river rhine. In 24 Essener Tagung Wasser und Abfall in Europa. Dresden: Wasser und Abfall in Europa. 1991, 141-146.

97. Pawlowski S, Jatzek J, Brauer T, Hempel K, Maisch R (2012) 34 years of investigation in the Rhine River at Ludwigshafen, Germany - trends in Rhine fish populations. Environ Sci Eur 24:1-8. https://doi.org/10.1186/ 2190-4715-24-28

98. Schulte-Wülwer-Leidig A (1993) The River Rhine. Development of the current water quality from a national point of view. Wasserwirtsch Wassertech 7:30-35

99. European Coffee Federation European Coffee Report 2018/2019. 2019. https://www.ecf-coffee.org/wp-content/uploads/2020/09/EuropeanCoffee-Report-2018-2019.pdf

100. Brandsma SH, Koekkoek JC, van Velzen MJM, de Boer J (2019) The PFOA substitute GenX detected in the environment near a fluoropolymer manufacturing plant in the Netherlands. Chemosphere 220:493-500. https://doi.org/10.1016/j.chemosphere.2018.12.135

101. Buck R, Franklin J, Berger U, Conder J, Cousins I, de Voogt P, Jensen A, Kannan K, Mabury S, van Leeuwen S (2011) Perfluoroalkyl and polyfluoroalkyl substances in the environment: terminology, classification, and origins. Integr Environ Assess Manag 7:513-541

102. OECD (2018) Toward a new comprehensive global database of per- and polyfluoroalkyl substances (PFASs): summary report on updating the OECD 2007 list of per- and polyfluoroalkyl substances (PFASs). Ser Risk Manag. 39:1-24

103. ECHA European Chemicals Agency https://echa.europa.eu/de/registryof-restriction-intentions/-/dislist/details/0b0236e18663449b.

104. United Nations Environment Programme UNEP Montreal Protocol on Substances that Deplete the Ozone Layer. 1989. https://treaties.un.org/ doc/publication/unts/volume\%201522/volume-1522-i-26369-english. pdf

105. Cousins IT, Goldenman G, Herzke D, Lohmann R, Miller M, Ng CA, Patton S, Scheringer M, Trier X, Vierke L (2019) The concept of essential use for determining when uses of PFASs can be phased out. Environ Sci Process Impacts 21:1803-1815

106. Cousins IT, De Witt JC, Glüge J, Goldenman G, Herzke D, Lohmann R, Miller M, Ng CA, Patton S, Scheringer M et al (2021) Finding essentiality feasible: common questions and misinterpretations concerning the "essential-use" concept. Environ Sci Process Impacts 23:1079-1087. https://doi.org/10.1039/D1EM00180A

107. European Environment Agency https://www.eea.europa.eu/highlights/ designing-safe-and-sustainable-products. https://www.eea.europa.eu/ highlights/designing-safe-and-sustainable-products. Accessed $3 \mathrm{Mar}$ 2022.

108. European Commission. https://ec.europa.eu/info/research-and-innov ation/research-area/industrial-research-and-innovation/key-enablingtechnologies/advanced-materials en. https://ec.europa.eu/info/resea rch-and-innovation/research-area/industrial-research-and-innovation/ key-enabling-technologies/advanced-materials_en. Accessed 3 Mar 2022.

109. Scheringer M, Trier X, Cousins IT, de Voogt P, Fletcher T, Wang Z, Webster TF (2014) Helsingør statement on poly- and perfluorinated alkyl substances (PFASs). Chemosphere 114:337-339. https://doi.org/10.1016/J. CHEMOSPHERE.2014.05.044

110. ChemSec. https://sinlist.chemsec.org/the-new-sin-list-chemicals/. Accessed 3 Mar 2022

111. ChemSec. https://sinlist.chemsec.org/the-science-behind/eloc-ident ification/pmt/. Accessed 3 Mar 2022.

112. Zimmerman JB, Anastas PT (2015) Toward substitution with no regrets: advances in chemical design are needed to create safe alternatives to harmful chemicals. Science 347:1198-1199. https://doi.org/10.1126/ SCIENCE.AAA0812

113. Horan TS, Pulcastro H, Lawson C, Gerona R, Martin S, Gieske MC, Sartain CV, Hunt PA (2018) Replacement bisphenols adversely affect mouse gametogenesis with consequences for subsequent generations. Curr Biol 28:2948-2954.e3. https://doi.org/10.1016/J.CUB.2018.06.070

114. Behringer, D.; Heydel, F; Gschrey, B.; Osterheld, S.; Schwarz, W.; Warncke, K.; Freeling, F.; Nödler, K.; Wasser, T.; Henne, S.; et al. Final report Persistent degradation products of halogenated refrigerants and blowing agents in the environment: type, environmental concentrations, and fate with particular regard to new halogenated substitutes with low global warming potential. 2021. https://www.umweltbundesamt.de/ sites/default/files/medien/5750/publikationen/2021-05-06_texte_732021_persistent_degradation_products.pdf

115. Zheng Z, Arp HPH, Peters G, Andersson PL (2020) Combining in silico tools with multicriteria analysis for alternatives assessment of hazardous chemicals: accounting for the transformation products of decaBDE and its alternatives. Environ Sci Technol. https://doi.org/10.1021/acs.est. Oc02593

116. Bunke, D.; Löw, C.; Moch, K.; Reihlen, A.; Reineke, N. Advancing REACHREACH and substitution Final report. https://www.umweltbundesamt. de/sites/default/files/medien/5750/publikationen/2021-01-14_texte_ 08-2021_advanching_reach_ap_10.pdf

117. Arp, H.P.H. Poll results and Commentary from the Third PMT workshop: Getting Control of PMT and vPvM substances under REACH https:// www.umweltbundesamt.de/sites/default/files/medien/362/dokum ente/third_pmt_workshop_polling_results_commentary_final.pdf. Accessed 3 Mar 2022.

118. Zarfl C, Hotopp I, Kehrein N, Matthies M (2012) Identification of substances with potential for long-range transport as possible substances of very high concern. Environ Sci Pollut Res Int 19:3152-3161. https:// doi.org/10.1007/S11356-012-1046-2

119. RIVM. https://www.rivm.nl/en/soil-and-water/simpletreat. Accessed 3 Mar 2022.

120. Rodgers TFM, Truong JW, Jantunen LM, Helm PA, Diamond ML (2018) Organophosphate ester transport, fate, and emissions in Toronto, Canada, estimated using an updated multimedia urban model. Environ Sci Technol 52:12465-12474. https://doi.org/10.1021/ACS.EST.8B02576

121. Franco A, Struijs J, Gouin T, Price O (2013) Evolution of the sewage treatment plant model SimpleTreat: applicability domain and data requirements. Integr Environ Assess Manag 9:560-568. https://doi.org/ 10.1002/IEAM. 1414

122. CEFIC. https://cefic-Iri.org/projects/eco-54-developing-a-tiered-model ing-framework-in-support-of-risk-assessment-of-chemical-substancesassociated-with-mobility-concerns/. Accessed 3 Mar 2022.

123. Droge S, Goss K-U (2012) Effect of sodium and calcium cations on the ion-exchange affinity of organic cations for soil organic matter. Environ Sci Technol 46:5894-5901. https://doi.org/10.1021/ES204449R

124. Matthies M, Solomon K, Vighi M, Gilman A, Tarazona JV (2016) The origin and evolution of assessment criteria for persistent, bioaccumulative and toxic (PBT) chemicals and persistent organic pollutants (POPs). Environ Sci Process Impacts 18:1114-1128. https://doi.org/10.1039/ c6em00311g 
125. Van Der Hoek JP, Bertelkamp C, Verliefde Bertelkamp ARD, Singhal N (2014) Drinking water treatment technologies in Europe: state of the art—Challenges—Research needs. J Water Supply Res Technol AQUA 63:124-130. https://doi.org/10.2166/aqua.2013.007

126. ECHA European Chemicals Agency. Support document for identification of perfluorobutane sulfonic acid and its salts as substances of very high concern because of their hazardous properties which cause probable serious effects to human health and the environment which give rise to an equi. 2019. https://echa.europa.eu/documents/10162/891ab 33d-d263-cc4b-0f2d-d84cfb7f424a

127. ECHA European Chemicals Agency. Member state committee support document for identification of 1,4-dioxane as a substance of very high concern because of its hazardous properties which cause probable serious effects to human health and the environment which give rise to an equivalent lev. 2021. https://echa.europa.eu/documents/10162/ e0466f47-be1a-6c72-2f1c-9e47665d8529

128. Dong H, Cuthbertson AA, Richardson SD (2020) Effect-directed analysis (EDA): a promising tool for nontarget identification of unknown disinfection byproducts in drinking water. Environ Sci Technol 54:12901292. https://doi.org/10.1021/ACS.EST.0C00014

129. Zheng Z, Arp HPH, Peters G, Andersson PL (2020) Combining in silico tools with multicriteria analysis for alternatives assessment of hazardous chemicals: accounting for the transformation products of decaBDE and its alternatives. Environ Sci Technol 55:1088-1098. https://doi.org/10. 1021/ACS.EST.0C02593

\section{Publisher's Note}

Springer Nature remains neutral with regard to jurisdictional claims in published maps and institutional affiliations.

\section{Submit your manuscript to a SpringerOpen ${ }^{\circ}$ journal and benefit from:}

- Convenient online submission

- Rigorous peer review

- Open access: articles freely available online

- High visibility within the field

- Retaining the copyright to your article

Submit your next manuscript at $\gg$ springeropen.com 